\title{
Study on the Load-Sharing Characteristics of an Aeronautical II-Stage Five-Branching Planets Gear Train Based on the Loaded Tooth Contact Analysis
}

\author{
Dong Hao ${ }^{D}{ }^{1},{ }^{1}$ Zong-de Fang ${ }^{D}{ }^{2},{ }^{2}$ and Ya-hui Hu${ }^{1}$ \\ ${ }^{1}$ School of Mechatronic Engineering, Xi'an Technological University, Xian 710021, China \\ ${ }^{2}$ College of Mechanical and Electrical Engineering, Northwestern Polytechnical University, Xi'an 710072, China \\ Correspondence should be addressed to Dong Hao; donghaofane@sina.com
}

Received 27 December 2017; Accepted 28 February 2018; Published 11 April 2018

Academic Editor: Yuri Vladimirovich Mikhlin

Copyright ( $\odot 2018$ Dong Hao et al. This is an open access article distributed under the Creative Commons Attribution License, which permits unrestricted use, distribution, and reproduction in any medium, provided the original work is properly cited.

\begin{abstract}
The aeronautical two-stage five-branching planets gear train is widely used in the internal decelerator of aeroengines and the main decelerator of helicopters. In order to study the load-sharing characteristics of the aeronautical two-stage five-branching planets gear train, a static load-sharing calculation model for this system is established. The loaded tooth contact analysis method is introduced in the static load-sharing calculation model, and the time-varying meshing stiffness condition of each gear pair is obtained. According to the characteristics of the whole system's power flow closed-loop characteristics, the twist angle deformation coordination condition of the system is established, which includes installation error, manufacturing error, and floating factor. Using the equivalent meshing error theory, the error of the gear manufacturing and the installation error of the system are analyzed. At the same time, the floating meshing error caused by the change of the meshing side gap caused by the floating of the sun gear and the inner ring gear is considered. The moment balance condition of the sun gear based on the floating of the spline gap is established. Combined with the coordination condition of torsion angle deformation, the torque of each gear pair is obtained. The load-sharing coefficient of the system is further calculated. The influence of the manufacturing error, the installation error, and the floating amount on the load-sharing coefficient is analyzed. The results show that the load-sharing coefficient of each planets gear varies with time when the manufacturing error and installation error alone affect the load-sharing characteristic. The sun gear floating can obviously improve the load-sharing performance. The correctness of the theoretical algorithm is verified by experiments. A new method of calculating the load-sharing characteristics of this system is put forward, which provides a theoretical basis for determining the load-sharing coefficient, reasonable allocation, and control tolerance on the design.
\end{abstract}

\section{Introduction}

Planets gear trains are widely used in the body of aircraft engine reducers and helicopter main reducers. The powersplit planets gear adopts the average load technology, which has the advantages of small size, lightweight, and strong carrying capacity. However, in practice, due to the unavoidable manufacturing and installation errors, as well as the elastic deformation of the components, the planets gear drive system cannot achieve a completely average load distribution. Therefore, it is very important to give full play to its advantages to solve the problem of uneven distribution of load among the planets gears. Due to the quality and reliability requirements of aeronautical products, it is unrealistic to employ additional averaging mechanisms. Therefore, there are mainly two ways to reduce the uneven distribution of load among the planets gears in the aviation industry. One is to improve the manufacturing and installation precision of gears and main parts, and elastic materials are used in transmission components to realize the system load sharing. The other way to improve the load-sharing performance is to take structural design measures. In other words, the automatic compensation of the various errors of each component in the working process is realized by the additional degree of freedom, so as to achieve the purpose of system load sharing.

The two-stage planets gear transmission system is characterized by a number of fixed-axis double-coupled planets common average distributions of input power. The system 
can achieve a great transfer of power and power load-sharing characteristics. Multiple planets gears are only subjected to one-way load. Due to the adoption of two-stage planets gears, planets gears are prevented from meshing with the sun gear and the ring gear at the same time, and the power of the system is decomposed into external gears and internal gears. This system overcomes the problems of traditional planetary transmission system planetary gears subjected to alternating loads, centrifugal forces caused by the rotation of the planet carrier, and intermittent lubrication of planet gears and their bearings.

Domestic and foreign scholars continue to explore and study the load-sharing characteristics of the power-split gear drive system. Kahraman [1] developed a nonlinear timevarying dynamic model of a planetary transmission with an arbitrary number of pinions and researched the loadsharing characteristics of planetary transmissions. Mo et al. [2] researched the influence of the eccentricity error, gear thickness error, base pitch error, assembly error, and bearing manufacturing error of gear components on multiple-split load sharing of two-stage planets gear system in consideration of displacement compatibility. Li et al. [3] established a mathematical model to predict the reliability of helicopter planetary gear train under the condition of partial load. The bad influence of unequal load sharing on planetary gear train is shown by prediction result and the reliability model is verified through a statistical analysis method of random censored data. Xu et al. [4] analyzed the load sharing of planetary gear train considering the flexibility of planet carrier. Li et al. [5] researched the effect predictions of star pinion geometry phase adjustments on dynamic load-sharing behaviors of differential face gear trains. Sheng et al. [6] analyzed the dynamic load-sharing behavior of transversetorsional coupled planetary gear train with multiple clearances. Park et al. [7] established that the model includes the nonlinear mesh stiffness of gears and the nonlinear stiffness of bearings as well as the flexibilities of the housing, planet carriers, and ring gears and analyzed the load sharing and distribution on the gear flank of wind turbine planetary gearbox. Kim et al. $[8,9]$ conducted an experimental study on the effect of carrier pinhole position errors on planet gear load sharing. They researched the effect analysis of carrier pinhole position error on the load sharing and load distribution of a planet gear. Iglesias et al. [10] researched the planetary gear profile modification design based on load-sharing modeling. Wang et al. [11] researched the load-sharing behavior and dynamic equations for planetary gear train transmission of wind turbine gearboxes. Spitas et al. [12] researched the experimental investigation of load sharing in multiple gear tooth contact using the stress-optical method of caustics. Pan et al. [13] researched the load-sharing characteristics of single-input gear split torque transmission based on synchronous angle. Zhang et al. [14] established a nonlinear dynamic model for analysis of the combined influences of nonlinear internal excitations on the load-sharing behavior of a compound planetary gear set. Qiu et al. [15] researched load-sharing characteristics of planetary gear transmission in horizontal axis wind turbines. Ye [16] established a dynamic differential equation of the NGW planetary gear train system with unequal moduli and pressure angles by taking into consideration the internal excitation caused by the eccentric error and tooth-frequency error of each gear and also researched the dynamic load-sharing behaviors of planetary gear train system with unequal moduli and pressure angles. Ye and Tsai [17] proposed a computerized approach based on the influence coefficient method for loaded tooth contact analysis of such gear transmission and analyzed the loaded tooth contact analysis of power-split gear drives considering shaft deformation and assembly errors. In addition, many scholars still study the load-sharing characteristics of the power-split gear transmission system [18-20].

After the research and analysis of the above scholars, it can be seen that the study of multilevel planets gear transmission system load-sharing characteristics for the rational design and successful use of the planets gear train is of great significance.

In this paper, the statics load-sharing model of the twostage five-branching planets gear train was established. By considering the characteristics of power flow closed loop, the torsional angle deformation coordination was deduced. Based on the condition of moment equilibrium, a loadsharing model of the system is established. Through the tooth surface contact simulation technology, the time-varying meshing stiffness is obtained in the load-sharing model. Using the theory of equivalent error meshing, the error factors of the system are analyzed comprehensively. The influence of manufacturing error, installation error, and floating factor on the load-sharing characteristics was revealed. The influence of each error on the load-sharing characteristics of the system was compared. The error factors which had the most influence on the load-sharing characteristics of the system were found. The simulation analysis method between the floating gear and the system load process is established, and the influence of the floating factors of the basic components on the load-sharing characteristics of the system is studied. Finally, the experimental verification is carried out and compared with the theoretical calculation results. A new method to calculate the load-sharing characteristics of twostage five-branching planets transmission system is proposed, which provides a theoretical basis for the design of loadsharing coefficient, reasonable process allocation, and control tolerance.

\section{Establishment of Equivalent Mechanical Model}

Figure 1 shows the three-dimensional schematic diagram and principle diagram of two-stage five-branching planets gear train. Here, the input torque $T_{\text {in }}$ is assigned to the I-stage planets gear $Z_{\mathrm{pI} i}(i=1,2, \ldots, 5)$ through the sun gear $Z_{\mathrm{s}}$ and then flowed into the ring gear $Z_{\mathrm{r}}$ through the II-stage planets gear $Z_{\mathrm{pII} i}$. The ring gear provides output torque $T_{\text {out }} \cdot n_{\mathrm{in}}$ is the input speed, and $n_{\text {out }}$ is the output speed.

Figure 2 is a schematic diagram of the mechanical balance between the various components of the two-stage fivebranching planets gear train. The planets gear mechanism is considered as a rigid body, and the I-stage sun gear and II-stage ring gear are considered as the basic floating 


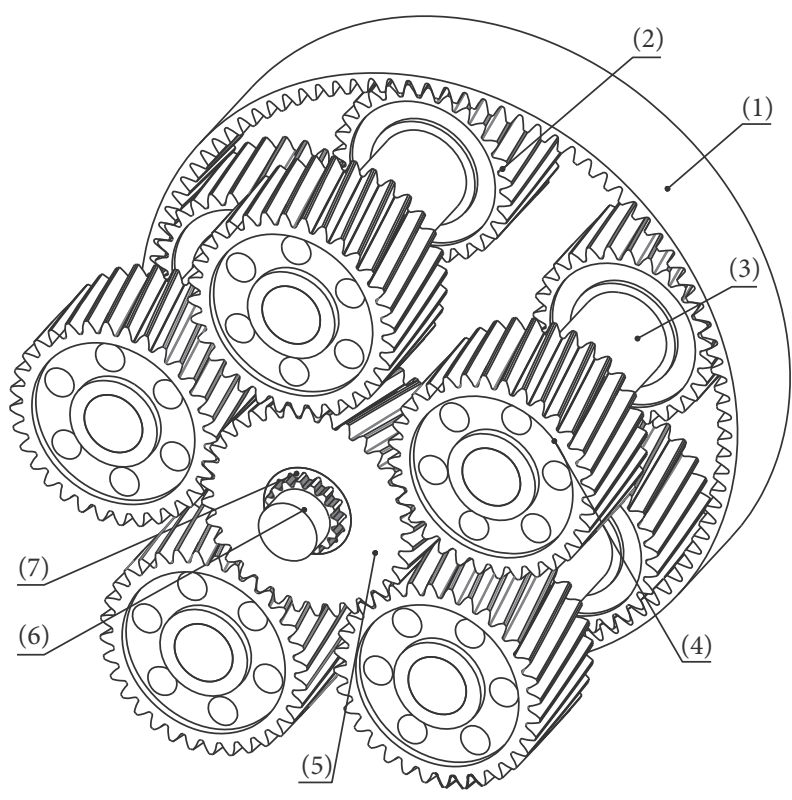

(a) Three-dimensional schematic diagram of the system

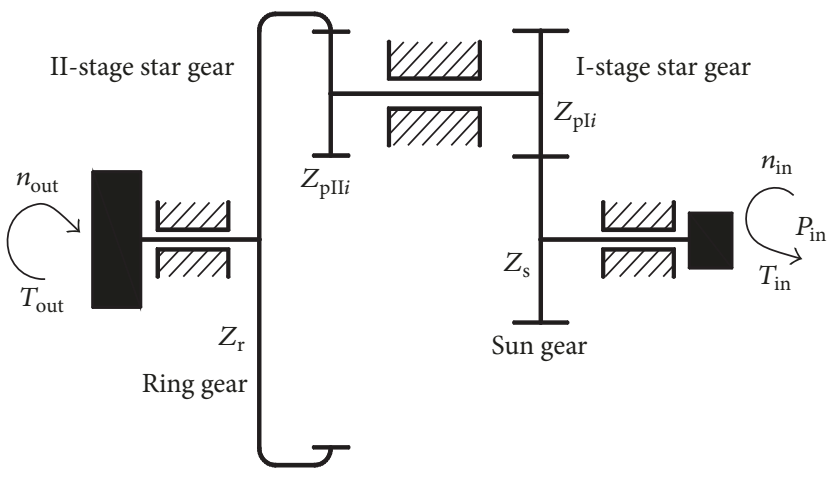

(b) The principle diagram of the system

FIGURE 1: Three-dimensional schematic diagram and principle diagram of two-stage five-branching planets gear train. (1) Ring gear, (2) II-stage planets gear, (3) connecting shaft, (4) I-stage planets gear, (5) sun gear, (6) outer spline, and (7) inner spline.

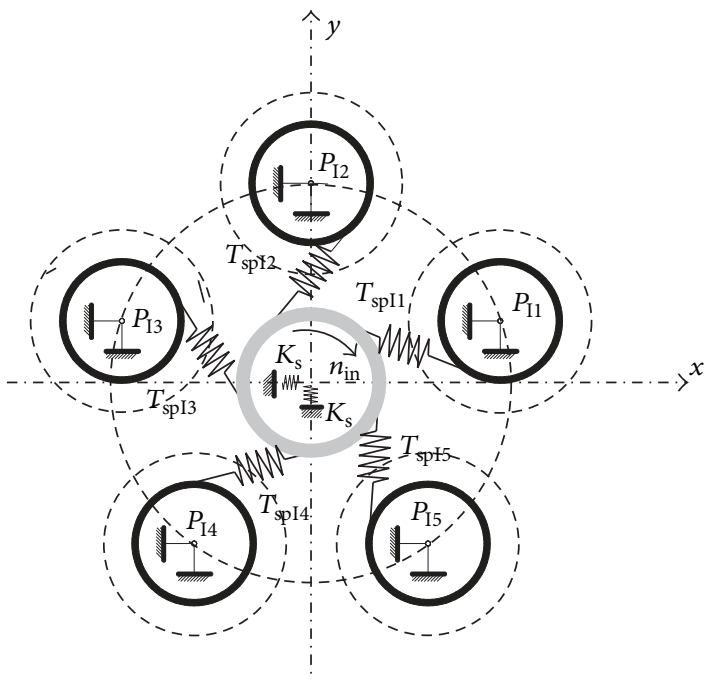

(a) Schematic diagram of the I-stage gear movement

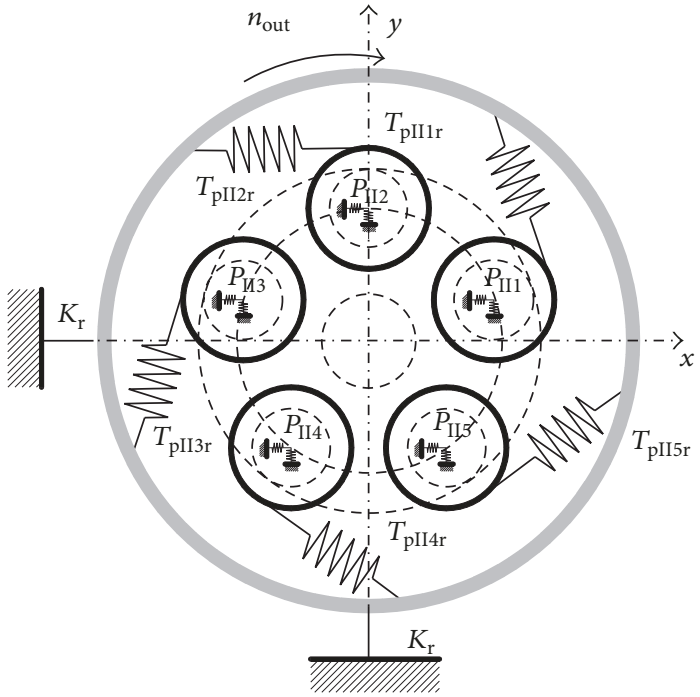

(b) Schematic diagram of the II-stage gear movement

FIgURE 2: Schematic diagram of the mechanical balance between the various components.

element. The elastic deformation and meshing stiffness of each gear pair in the system are replaced by the equivalent spring model. $K_{\mathrm{s}}$ and $K_{\mathrm{r}}$ represent the equivalent elastic support stiffness at the sun gear and the internal ring gear, respectively. $P_{\mathrm{I} i}$ is the I-stage planets gear. $P_{\mathrm{II} i}$ is the II-stage planets gear. $T_{\mathrm{spI} i}$ is the acting torque between the sun gear and the I-stage planets gear. $T_{\text {pIIir }}$ is the acting torque between the II-stage planets gear and the ring gear.

According to the torque balance between the various components of the system shown in Figure 2, the torque balance equation is shown below:

$$
\begin{aligned}
T_{\mathrm{in}}+\sum_{i}^{5} T_{\mathrm{spIi}}(k) & =0, \\
T_{\mathrm{psI} i}(k)+T_{\mathrm{pIIir}}(k) & =0, \\
& (i=1,2, \ldots, 5) .
\end{aligned}
$$

$T_{\mathrm{psI} i}(k)(i=1,2, \ldots, 5)$ is the torque of the I-stage planets gear acting on the sun gear at the $k$ th meshing position in a meshing cycle. $k$ represents the sequence number of the meshing position. When carrying out gear teeth contact 


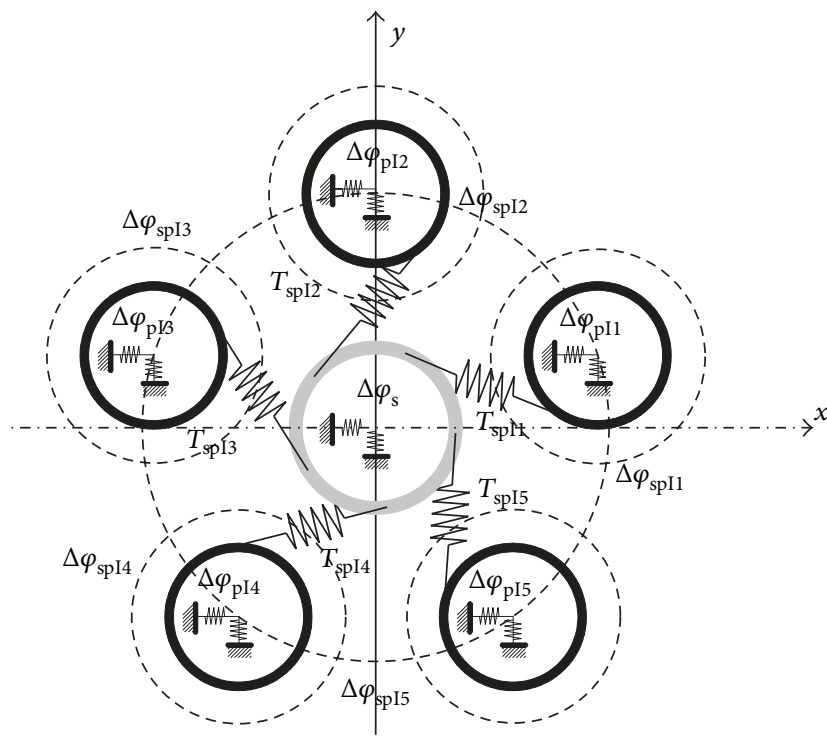

(a) I-stage gear pair

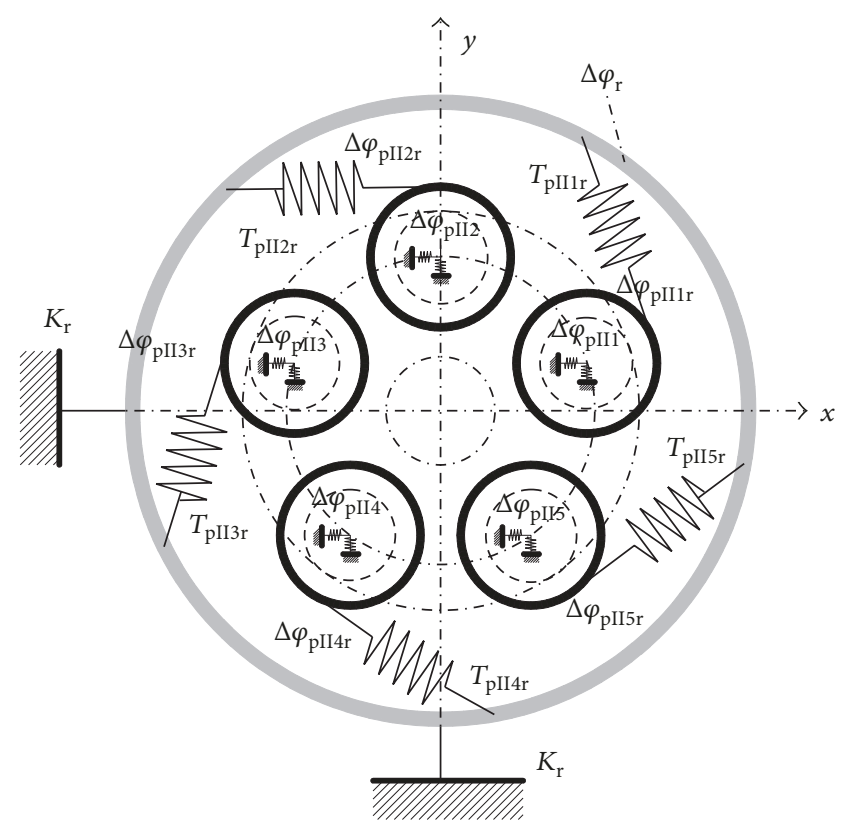

(b) II-stage gear pair

FIGURE 3: Relationship diagram between the torsion angles of each gear of the system.

simulation analysis, a tooth surface engagement period is divided into 5 equal parts; thus, $k=1,2, \ldots, 5$.

The relationship between the action moment $T_{\mathrm{spli}}(k)$ and the reaction moment $T_{\mathrm{psI} i}(k)$ can be expressed as follows:

$$
T_{\mathrm{psI} i}(k)=-\frac{r_{\mathrm{bpI} i}}{r_{\mathrm{bs}}} T_{\mathrm{psI} i}(k) \quad(i=1,2, \ldots, 5) .
$$

From formula (1) and formula (2), the expression of the moment equilibrium relationship can be obtained as shown below:

$$
\begin{array}{r}
T_{\mathrm{in}}+\sum_{i}^{5} T_{\mathrm{spI} i}(k)=0, \\
-\frac{r_{\mathrm{bpI} i}}{r_{\mathrm{bs}}} T_{\mathrm{spI} i}(k)+T_{\mathrm{pIIir}}(k)=0,
\end{array}
$$

$$
(i=1,2, \ldots, 5)
$$

In formula (3), $r_{\mathrm{bpI} i}$ is the base circle radius of the I-stage planets gear, $r_{\mathrm{bs}}$ is the base circle radius of sun gear, $T_{\mathrm{in}}$ is input torque, and $T_{\mathrm{pIIir}}(\mathrm{k})$ is the torque of the II-stage planets gear acting on the ring gear.

Figure 3 shows the relationship diagram between the torsion angles of each gear of the system. $\Delta \varphi_{\mathrm{pI} i}$ is the torsion angle of the I-stage planets gear. $\Delta \varphi_{\mathrm{pII} i}$ is the torsion angle of the II-stage planets gear. $\Delta \varphi_{\mathrm{s}}$ is the torsion angle of the sun gear. $\Delta \varphi_{\mathrm{r}}$ is the torsion angle of the ring gear. $\Delta \varphi_{\text {spli }}$ is the torsion angular distortion of the sun gear under the influence of torque relative to the I-stage planets gear. $\Delta \varphi_{\text {spI }}$ is a function of $T_{\mathrm{spIi}}(k) . \Delta \varphi_{\mathrm{pIIir}}$ is the angular distortion of the II-stage planets gear under the influence of torque relative to the ring gear. $\Delta \varphi_{\mathrm{pIIir}}$ is a function of $T_{\mathrm{pIIir}}(k)$.
According to the mechanical conditions, the torsion meshing angle of each gear pair meets the following mechanical relationship:

$$
\begin{gathered}
\Delta \varphi_{\mathrm{spIi}}\left[T_{\mathrm{spIi}}(k)\right]=\Delta \varphi_{\mathrm{s}}-\left(\frac{r_{\mathrm{bpIi}}}{r_{\mathrm{bs}}}\right) \Delta \varphi_{\mathrm{pI} i}, \\
\Delta \varphi_{\mathrm{pIIir}}\left[T_{\mathrm{pIIir}}(k)\right]=\Delta \varphi_{\mathrm{pIIi}}-\left(\frac{r_{\mathrm{br}}}{r_{\mathrm{bpII} i}}\right) \Delta \varphi_{\mathrm{r}} .
\end{gathered}
$$

Here, $r_{\mathrm{bpII}}$ is the base circle radius of the II-stage planets gear; $r_{\mathrm{br}}$ is the base circle radius of ring gear.

$\Delta \varphi_{i}(i=1,2, \ldots, 5)$ is the angle error of the gear $i$, and $\Delta \varphi_{i j}\left(T_{i j}(k)\right)$ indicates the angle microdisplacement of the gear $i$ relative to the gear $j$; that is, $\Delta \varphi_{i j}\left(T_{i j}(k)\right)$ is loaded transmission error. $\Delta \varphi_{i j}\left(T_{i j}(k)\right)$ is a function of $T_{i j}(k)$. $\Delta \varphi_{i j}\left(T_{i j}(k)\right)$ is derived from the tooth contact analysis and the loaded tooth contact analysis and meets the following relation with the integrated time-varying meshing stiffness $K_{\mathrm{m} i j}(k)$ of the gear pairs:

$$
\Delta \varphi_{i j}\left[T_{i j}(k)\right]=\frac{T_{i j}(k)}{K_{\mathrm{m} i j}(k) r_{\mathrm{b} i}^{2} \cos a_{\mathrm{n}}} .
$$

In the formula, $K_{\mathrm{mij}}(k)$ is the integrated time-varying meshing stiffness of each gear pair $i j$, and $a_{\mathrm{n}}$ is the normal meshing pressure angle of each gear.

The transmission error of each meshing pair is converted to the equivalent meshing angle error relative to the sun gear. 


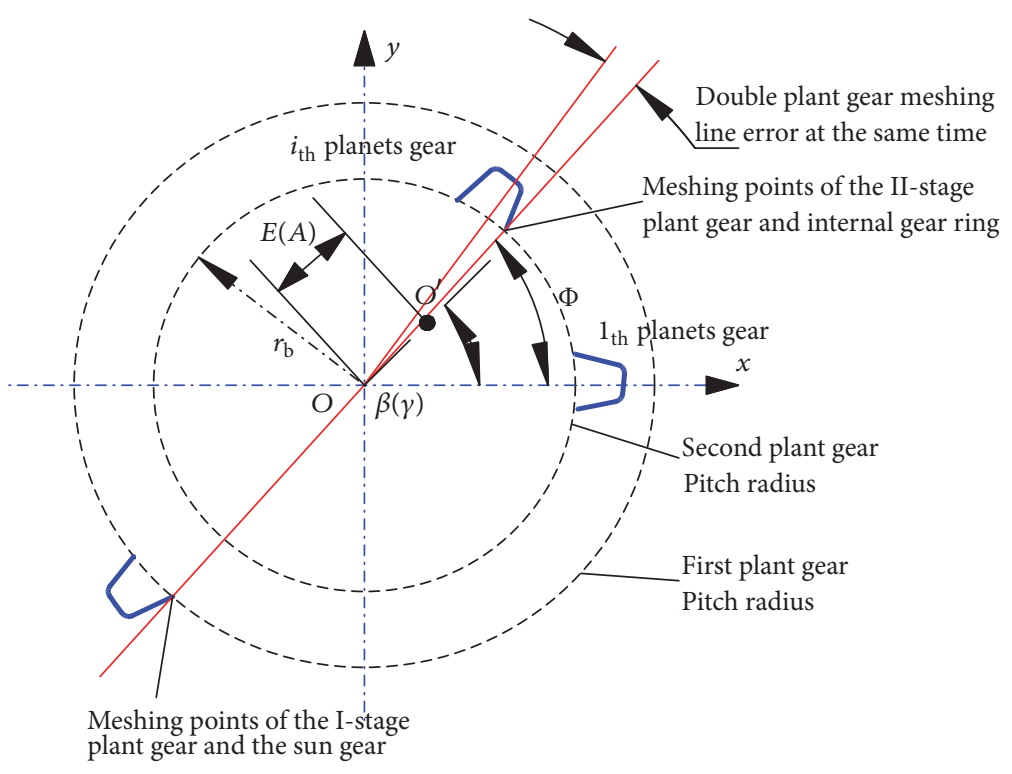

FIGURE 4: Schematic diagram of manufacturing or installation error of $E(A)$.

$$
\begin{array}{r}
\Delta \varphi_{i}=\Delta \varphi_{\mathrm{spI} 1}\left[T_{\mathrm{spI} 1}(k)\right]+\frac{r_{\mathrm{bpII} 1}}{r_{\mathrm{bs}}} \Delta \varphi_{\mathrm{pIIl}}\left[T_{\mathrm{pII} 1 \mathrm{r}}(k)\right] \\
=\Delta \varphi_{\mathrm{spI} i}\left[T_{\mathrm{spI} i}(k)\right]+\frac{r_{\mathrm{bpII} i}}{r_{\mathrm{bs}}} \Delta \varphi_{\mathrm{p} I i \mathrm{r}}\left[T_{\mathrm{pIIir}}(k)\right] \\
(i=2, \ldots, n) .
\end{array}
$$

Due to $\Delta \varphi_{1}=\Delta \varphi_{2}=\Delta \varphi_{3}=\Delta \varphi_{4}=\Delta \varphi_{5}$, the deformation coordination condition can be obtained as follows:

$$
\begin{aligned}
& \Delta \varphi_{\mathrm{spI} 1}\left[T_{\mathrm{spI} 1}(k)\right]+\frac{r_{\mathrm{bpII} 1}}{r_{\mathrm{bs}}} \Delta \varphi_{\mathrm{pII} 1 \mathrm{r}}\left[T_{\mathrm{pII} 1 \mathrm{r}}(k)\right] \\
& =\Delta \varphi_{\mathrm{spI} 2}\left[T_{\mathrm{spI} 2}(k)\right]+\frac{r_{\mathrm{bpII} 2}}{r_{\mathrm{bs}}} \Delta \varphi_{\mathrm{pII} 2 \mathrm{r}}\left[T_{\mathrm{pII} 2 \mathrm{r}}(k)\right] \text {, } \\
& \Delta \varphi_{\mathrm{spI} 1}\left[T_{\mathrm{spIl}}(k)\right]+\frac{r_{\mathrm{bpIIl}}}{r_{\mathrm{bs}}} \Delta \varphi_{\mathrm{pIIl}}\left[T_{\mathrm{pIIl}}(k)\right] \\
& =\Delta \varphi_{\mathrm{spI} 3}\left[T_{\mathrm{spI} 2}(k)\right]+\frac{r_{\mathrm{bpII} 3}}{r_{\mathrm{bs}}} \Delta \varphi_{\mathrm{pII} 3 \mathrm{r}}\left[T_{\mathrm{pII} 3 \mathrm{r}}(k)\right] \text {, } \\
& \Delta \varphi_{\mathrm{spI}}\left[T_{\mathrm{spI} 1}(k)\right]+\frac{r_{\mathrm{bpII1}}}{r_{\mathrm{bs}}} \Delta \varphi_{\mathrm{pIIl}}\left[T_{\mathrm{pIIlr}}(k)\right] \\
& =\Delta \varphi_{\mathrm{spI} 4}\left[T_{\mathrm{spI} 4}(k)\right]+\frac{r_{\mathrm{bpII} 4}}{r_{\mathrm{bs}}} \Delta \varphi_{\mathrm{pII} 4 \mathrm{r}}\left[T_{\mathrm{pII} 4 \mathrm{r}}(k)\right] \text {, } \\
& \Delta \varphi_{\mathrm{spI} 1}\left[T_{\mathrm{spIl}}(k)\right]+\frac{r_{\mathrm{bpII}}}{r_{\mathrm{bs}}} \Delta \varphi_{\mathrm{pIIl}}\left[T_{\mathrm{pIIlr}}(k)\right] \\
& =\Delta \varphi_{\mathrm{spI} 5}\left[T_{\mathrm{spI} 5}(k)\right]+\frac{r_{\mathrm{bpII} 5}}{r_{\mathrm{bs}}} \Delta \varphi_{\mathrm{pII} 5 \mathrm{r}}\left[T_{\mathrm{pII} 5 \mathrm{r}}(k)\right] .
\end{aligned}
$$

Combining formula (2), formula (4), and formula (6), the calculation model of torque distribution under rigid conditions is obtained. When given the input torque $T_{\text {in }}$ and the time-varying meshing stiffness $K_{\mathrm{m} i j}(k)$ of each gear pair, the torque forces $T_{\mathrm{spI} i}(k)$ and $T_{\mathrm{pIIir}}(k)$ of each gear pair can be calculated.

\section{Comprehensive Meshing Error Analysis}

The equivalent combined meshing errors of the planets gear transmission system are composed of two kinds of errors. The first one is the cumulative meshing backlash caused by the manufacturing and installation errors of the components, that is, cumulative mesh error. The other is the floating meshing error caused by the floating of each component.

3.1. Cumulative Errors Caused by Manufacturing and Installation Errors. The manufacturing errors that affect the load distribution of the planets gear system include the eccentric error of the center of the sun gear, the planets gear, and the ring gear. The installation error mainly includes the assembly error of the center of the sun gear, the planets gear, and the ring gear. The eccentricity error and assembly error are represented by $E$ and $A$, respectively. The direction of each error is represented by $\beta$ and $\gamma$. The subscript symbols s, $\mathrm{pI} i, \mathrm{pII} i$, and $\mathrm{r}$ are, respectively, represent the sun gear, the I-stage planets gear, the II-stage planets gear, and the ring gear.

Figure 4 is the schematic diagram of manufacturing or assembly error $E(A)$.

Here, $\omega_{\mathrm{s}}, \omega_{\mathrm{p}}$, and $\omega_{\mathrm{r}}$ are the angular velocities of sun gear, planets gear, and ring gear.

$\alpha_{w}$ and $\alpha_{\mathrm{n}}$ are the meshing pressure angles of external gear meshing and internal gear meshing.

$\phi_{i}$ refers to the phase angle of the $i_{\text {th }}$ planets gear relative to $1_{\text {th }}$ planets gear. $\phi_{i}=2 \pi(i-1) / 5$; $t$ is the response time.

(1) Angular Displacement Caused by Equivalent Meshing Error of I-Stage Gear Pairs. The angular displacement $\varphi_{E s i}$ caused by the eccentric error $E_{\mathrm{s}}$ of the sun gear is 


$$
\varphi_{\mathrm{E} s i}=-E_{\mathrm{s}} \sin \frac{\left(\omega_{\mathrm{s}} t+\beta_{\mathrm{s}}+\alpha_{w}-\phi_{i}\right)}{r_{\mathrm{bs}}} .
$$

The angular displacement $\varphi_{A s i}$ caused by the installation error $A_{\mathrm{s}}$ of the sun gear is

$$
\varphi_{A s i}=-A_{\mathrm{s}} \sin \frac{\left(\gamma_{\mathrm{s}}+\alpha_{w}-\phi_{i}\right)}{r_{\mathrm{bs}}} .
$$

The angular displacement $\varphi_{\mathrm{EpI} i}$ caused by the eccentric error $E_{\mathrm{pI} i}$ of the I-stage planets gear $i$ is

$$
\varphi_{\mathrm{EpI} i}=-E_{\mathrm{pI} i} \sin \frac{\left(-\omega_{\mathrm{p}} t+\beta_{\mathrm{pI} i}+\alpha_{w}\right)}{r_{\mathrm{bpI} i}} .
$$

The angular displacement $\varphi_{\text {ApI } i}$ caused by the installation error $A_{\mathrm{pI} i}$ of the I-stage planets gear $i$ is

$$
\varphi_{\mathrm{ApI} i}=-A_{\mathrm{pI} i} \sin \frac{\left(\gamma_{\mathrm{pI} i}+\alpha_{w}\right)}{r_{\mathrm{bpI} i}} .
$$

(2) Angular Displacement Caused by Equivalent Mesh Error in Stage II. The angular displacement $\varphi_{\mathrm{EpII} i}$ caused by the eccentric error $E_{\mathrm{pII} i}$ of the II-stage planets gear $i$ is

$$
\varphi_{\mathrm{EpII} i}=E_{\mathrm{pII} i} \sin \frac{\left(-\omega_{\mathrm{p}} t+\beta_{\mathrm{pII} i}-\alpha_{\mathrm{n}}\right)}{r_{\mathrm{bpII} i}} .
$$

The angular displacement $\varphi_{\text {ApII } i}$ caused by the installation error $A_{\mathrm{pII} i}$ of the II-stage planets gear $i$ is

$$
\varphi_{\mathrm{ApII} i}=A_{\mathrm{pII} i} \sin \frac{\left(\gamma_{\mathrm{pII} i}-\alpha_{\mathrm{n}}\right)}{r_{\mathrm{bpII} i}} .
$$

The angular displacement $\varphi_{E \mathrm{r}}$ caused by the eccentric error $E_{\mathrm{r}}$ of the ring gear is

$$
\varphi_{E \mathrm{r} i}=E_{\mathrm{r}} \sin \frac{\left(-\omega_{\mathrm{r}} t+\beta_{\mathrm{r}}-\alpha_{\mathrm{n}}-\phi_{i}\right)}{r_{\mathrm{br}}} .
$$

The angular displacement $\varphi_{\text {Ar }}$ caused by the installation error $A_{\mathrm{r}}$ of the ring gear is

$$
\varphi_{\text {Ari }}=A_{\mathrm{r}} \sin \frac{\left(\gamma_{\mathrm{r}}-\alpha_{\mathrm{n}}-\phi_{i}\right)}{r_{\mathrm{br}}} .
$$

(3) Angular Displacement Caused by Eccentric Error of Bearing. The angular displacement $\varphi_{E \mathrm{bs}}$ caused by the eccentric error $E_{\mathrm{bs}}$ of bearing of the sun gear is

$$
\varphi_{E \mathrm{bs}}=-E_{\mathrm{bs}} \sin \frac{\left(\omega_{\mathrm{s}} t+\beta_{\mathrm{bs}}+\alpha_{w}-\phi_{i}\right)}{r_{\mathrm{bs}}} .
$$

The angular displacement $\varphi_{E b p I i}$ caused by the eccentric error $E_{\mathrm{bpI} i}$ of bearing of the I-stage planets gear is

$$
\varphi_{\mathrm{EbpI} i}=\mathrm{E}_{\mathrm{bpI} i} \sin \frac{\left(-\omega_{\mathrm{p}} t+\beta_{\mathrm{bp} i}+\alpha_{w}\right)}{r_{\mathrm{bpI} i}} .
$$

The angular displacement $\varphi_{E b p I I}$ caused by the eccentric error $E_{\mathrm{bpII} i}$ of bearing of the II-stage planets gear is

$$
\varphi_{\mathrm{EbpII} i}=E_{\mathrm{bpII} i} \sin \frac{\left(-\omega_{\mathrm{p}} t+\beta_{\mathrm{bpII} i}-\alpha_{\mathrm{n}}\right)}{r_{\mathrm{bpII} i}} .
$$

The angular displacement $\varphi_{E b r i}$ caused by the eccentric error $E_{\mathrm{br}}$ of bearing of the ring gear is

$$
\varphi_{\text {Ebri }}=E_{\mathrm{br}} \sin \frac{\left(-\omega_{\mathrm{r}} t+\beta_{\mathrm{br}}-\alpha_{\mathrm{n}}-\phi_{i}\right)}{r_{\mathrm{br}}} .
$$

The sum of the above-mentioned equivalent meshing errors is obtained.

The cumulative angular displacement generated by the manufacturing error and installation error in stage I and stage II is shown as follows:

$$
\begin{gathered}
\varphi_{\mathrm{spl} i}=\varphi_{E s i}+\varphi_{A s i}+\varphi_{E \mathrm{pl} i}+\varphi_{A \mathrm{AI} i}+\varphi_{E \mathrm{~b} s i}+\varphi_{E \mathrm{bpI} i}, \\
\varphi_{\mathrm{pIIir}}=\varphi_{E \mathrm{r} i}+\varphi_{A r i}+\varphi_{E \mathrm{pII} i}+\varphi_{A \mathrm{pII} i}+\varphi_{E \mathrm{br} i}+\varphi_{E \mathrm{bpI} i} .
\end{gathered}
$$

There is also a kind of change that can cause the comprehensive engagement error change caused by gap changes $\varphi_{\mathrm{s}}$ and $\varphi_{\mathrm{r}}$ of basic floating elements.

It is assumed that the floating displacement of the center of the sun gear is $x_{\mathrm{s}}$ and $y_{\mathrm{s}}$ along $x$ and $y$ directions. The floating displacement of the center of the ring gear is $x_{\mathrm{r}}$ and $y_{\mathrm{r}}$ along $x$ and $y$ directions.

$$
\begin{aligned}
\varphi_{\mathrm{s} i} & =-\frac{\left(x_{\mathrm{s}} \cos A_{i}+y_{\mathrm{s}} \sin A_{i}\right)}{r_{\mathrm{bs}}}, \\
\varphi_{\mathrm{r} i} & =-\frac{\left(x_{\mathrm{r}} \cos B_{i}+y_{\mathrm{r}} \sin B_{i}\right)}{r_{\mathrm{br}}} .
\end{aligned}
$$

$A_{i}$ is the meshing line direction angle of the sun gear and the I-stage planets gear; $B_{i}$ is the meshing line direction angle of the I-stage planets gear and the ring gear. $A_{i}$ and $B_{i}$ are as follows:

$$
\begin{aligned}
A_{i} & =\frac{\pi}{2}-\alpha_{w}+\phi_{i}, \\
B_{i} & =\frac{\pi}{2}+\alpha_{\mathrm{n}}+\phi_{i} .
\end{aligned}
$$

Integral meshing error $\varphi^{E}$ spIi of sun gear and the I-stage planets gear is as follows:

$$
\begin{aligned}
\varphi_{\mathrm{spI} i}^{E} & =\Delta \varphi_{\mathrm{spI} i}\left[T_{\mathrm{spI} i}(k)\right]+\varphi_{\mathrm{spI} i}+\varphi_{\mathrm{s} i} \\
& =\frac{\left[T_{\mathrm{spI} i}(k)\right]}{K_{\mathrm{mspI} i}(k) r_{\mathrm{bs}}^{2} \cos a_{\mathrm{n}}}+\varphi_{\mathrm{spI} i}+\varphi_{\mathrm{s} i}
\end{aligned}
$$

Here, $K_{\mathrm{mspI} i}(k)$ is the integrated time-varying meshing stiffness of sun gear and I-stage planets gear $i$.

Integral meshing error $\varphi^{E}{ }_{\text {spII } i}$ of the II-stage planets gear and ring gear is as follows:

$$
\begin{aligned}
\varphi_{\mathrm{pIIir}}^{E} & =\Delta \varphi_{\mathrm{pIIir}}\left[T_{\mathrm{pIIir}}(k)\right]+\varphi_{\mathrm{pIIir}}+\varphi_{\mathrm{ri}} \\
& =\frac{\left[T_{\mathrm{pIIir}}(k)\right]}{K_{\mathrm{mpIIir}}(k) r_{\mathrm{bpII} i}^{2} \cos a_{\mathrm{n}}}+\varphi_{\mathrm{pIIir}}+\varphi_{\mathrm{ri}} .
\end{aligned}
$$




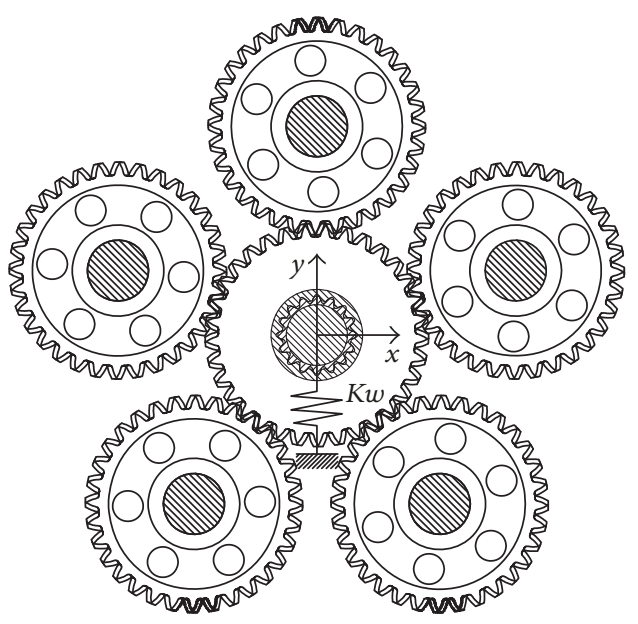

FIGURE 5: Closed mechanical relation of floating sun gear based on the spline gap floating.

Here, $K_{\text {mpIir }}(k)$ is the integrated time-varying meshing stiffness of II-stage planets gear $i$ and ring gear.

\subsection{Floating Equilibrium Condition of Basic Component}

\subsubsection{The Sun Gear Floating Equilibrium Condition Based on} the Spline Space. The sun gear can float freely through the gap between the splines. If the floating sun gear is unbalanced in force, the short spline and its side clearance allow the basic members to make radial and deflection displacement, so that the load distribution tends to be uniform, so as to achieve the average load distribution. The structure based on the floating of the spline gap has a good centering effect and can transmit large torque. The closed mechanical relation of floating sun gear based on the spline gap floating is shown in Figure 5.

The sun gear is balanced under the I-stage planets gear meshing force $F_{\mathrm{spI} i}$ and the spline axis supporting force. The supporting rigidity of floating sun gear is shown in Figure 6

With the spline transmit torque, friction will be produced between internal and external splines, which can be represented as $F_{\mathrm{m}}=\tau F_{\mathrm{m}}$, where $F_{\mathrm{m}}$ is the positive pressure between internal and external splines and $\tau$ is the friction coefficient.

When the sun gear is floating, the floating quantum is shown as follows:

$$
R_{\mathrm{s}}=\sqrt{\left(x_{\mathrm{s}}^{2}+y_{\mathrm{s}}^{2}\right)}
$$

Here, $x_{\mathrm{s}}$ and $y_{\mathrm{s}}$ are the floating quantum along the $x$ direction and $y$ direction, respectively.

When the bearing reaction force is less than the friction force $F_{\mathrm{m}}$, there will be no slip between the inner spline and the outer spline. When the supporting force is greater than the friction force $F_{\mathrm{m}}$, the internal spline and the external spline will produce a slip, which is adapted to the position of the floating gear, that is, the $S_{1}-S_{2}$ range. When the slip amount exceeds $S_{2}$, the internal and external splines eliminate the radial clearance, and the position of the small gear is determined by the bending deformation of the input

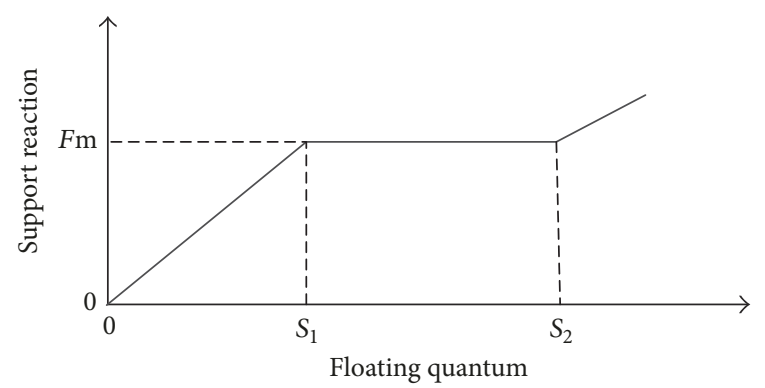

FIGURE 6: Supporting rigidity of floating sun gear.

shaft. $S_{1}-S_{2}$ is the radial clearance for internal and external splines.

$F_{\mathrm{H} x \mathrm{~s}}$ and $F_{\mathrm{H} y s}$ represent the support reaction of floating pinion projected on the $x$-axis and $y$-axis, respectively, and can be represented as

$$
\begin{aligned}
& F_{\mathrm{H} x s} \\
& = \begin{cases}-K_{w} \cdot R_{s} \cdot \cos \left(\xi_{s}^{(n)}\right) & 0 \leq R_{s}<S_{1} \\
-F_{\mathrm{m}} \cdot \cos \left(\xi_{s}^{(n)}\right) & S_{1} \leq R_{s} \leq S_{2} \\
-\left[F_{\mathrm{m}}+K_{w} \cdot\left(R_{s}-S_{2}\right)\right] \cdot \cos \left(\xi_{s}^{(n)}\right) & R_{s}>S_{2},\end{cases} \\
& F_{\mathrm{H} y s} \\
& = \begin{cases}-K_{w} \cdot R_{\mathrm{s}} \cdot \sin \left(\xi_{s}^{(n)}\right) & 0 \leq R_{s}<S_{1} \\
-F_{\mathrm{m}} \cdot \sin \left(\xi_{s}^{(n)}\right) & S_{1} \leq R_{s} \leq S_{2} \\
-\left[F_{\mathrm{m}}+K_{w} \cdot\left(R_{s}-S_{2}\right)\right] \cdot \sin \left(\xi_{s}^{(n)}\right) & R_{s}>S_{2},\end{cases}
\end{aligned}
$$

where $K_{w}$ is flexural rigidity of spline shaft; $\xi_{s}$ is direction angle of vector of $x_{s}$ and $y_{s}$.

The support equilibrium conditions of the floating sun gear can be represented as

$$
\begin{aligned}
& \sum_{i=1}^{5}\left[\frac{T_{\mathrm{spI} i}}{r_{\mathrm{bs}}} \cdot \cos \chi_{\mathrm{spI} i}\right]+F_{\mathrm{H} x s}=0, \\
& \sum_{i=1}^{5}\left[\frac{T_{\mathrm{spI} i}}{r_{\mathrm{bs}}} \cdot \cos \chi_{\mathrm{spI} i}\right]+F_{\mathrm{H} y s}=0,
\end{aligned}
$$

$$
(i=1,2, \ldots, 5) \text {. }
$$

The equilibrium conditions of the floating sun gear are used as the optimization objective. The unknown quantity of the required solution of the component is the optimization variable. $\left(x_{s}, y_{s}\right)$ is used as the optimization variable in the equilibrium position of the floating sun gear. The equilibrium condition of elastic support, the condition of moment equilibrium, and the condition of deformation coordination are used as the constraint conditions. A nonlinear mathematical model of the gap based on the floating is established.

3.2.2. The Ring Gear Floating Equilibrium Condition. The floating balance condition of the ring gear is shown below: 


$$
\begin{aligned}
& \sum_{i=1}^{5} \frac{T_{\mathrm{pIIir}}}{r_{\mathrm{bp}}} \cdot \cos \chi_{\mathrm{pIIir}}+K_{\mathrm{r}} x_{\mathrm{r}}=0, \\
& \sum_{i=1}^{5} \frac{T_{\mathrm{pIIir}}}{r_{\mathrm{bp}}} \cdot \sin \chi_{\mathrm{pIIir}}+K_{\mathrm{r}} y_{\mathrm{r}}=0,
\end{aligned}
$$

$$
(i=1,2, \ldots, 5)
$$

Here, $x_{\mathrm{r}}$ and $y_{\mathrm{r}}$ are the floating quantum of ring gear along the $x$ direction and $y$ direction, respectively.

The torque $T_{i j}$ of the gear pair is obtained.

The load-sharing coefficient of the I-stage planets gear is shown as follows:

$$
J_{\mathrm{pI} i}=\frac{T_{\mathrm{spl} i}}{\left(T_{\mathrm{in}} / 5\right)} \quad(i=1,2, \ldots, 5) .
$$

The load-sharing coefficient of the II-stage planets gear is shown as follows:

$$
J_{\mathrm{pII} i}=\frac{T_{\mathrm{pII} i r}}{\left(r_{\mathrm{bpI} i} / \mathrm{r}_{\mathrm{bpII} i}\right)\left(T_{\mathrm{in}} / 5\right)} \quad(i=1,2, \ldots, 5) .
$$

The load-sharing coefficient of the system is shown below:

$$
J=\max \left(J_{\mathrm{pI} i}, J_{\mathrm{pII} i}\right) \quad(i=1,2, \ldots, 5) .
$$

\section{Calculation of Time-Varying Meshing Stiffness Based on Loaded Tooth Contact Analysis}

The transmission error of the gear bearing in meshing is mainly composed of three parts corresponding to the geometric transmission error $\delta_{1}$, the bending deformation $\delta_{2}$, and the contact deformation $\delta_{3}$. The geometric transmission error $\delta_{1}$ is formed by the design and processing of the tooth surface, which is independent of the size of the load, and can be expressed as a constant term at the fixed position of the meshing. The geometric transmission errors $\delta_{1}$ can be expressed as $\delta_{1}(T(k))=a$.

The calculation formula of cantilever beam of Westinghouse is used as the basis for calculating the bending deformation of gear teeth [21]:

$$
\begin{aligned}
\delta_{b} & =\frac{p h^{3}}{3 E I}\left\{1+1.3\left(\frac{t}{h}\right)+[0.25+0.75(1-\mu)]\left(\frac{t}{h}\right)^{2}\right. \\
& \left.+0.35\left(\frac{t}{h}\right)^{3}\right\} .
\end{aligned}
$$

Here, $p$ is the load at the meshing point; $t$ is the normal tooth thickness at the meshing point; $h$ is the tooth height at the meshing point; $E$ is the modulus of elasticity; $\mu$ is Poisson's ratio; $I$ is an orthogonal inertia moment; $b_{w}$ is the tooth width of the tooth in the cutting plane at the point of engagement.

It can be seen from the above formula that the bending deformation has a linear relationship with the load $T(k)$. Here, $\delta_{2}(T(k))=b T(k)$.

According to the theory of elasticity, the contact deformation of the spiral bevel gear pair is the point contact problem of elastic mechanics. The maximum amount $\delta_{\mathrm{H}}$ of deformation at the contact point of the tooth surface can be expressed as the following formula:

$$
\delta_{\mathrm{H}}=\mathrm{c}_{\alpha}\left(\frac{9 p^{2} A}{32}\left(\frac{1-\mu_{1}^{2}}{E_{1}}+\frac{1-\mu_{2}^{2}}{E_{2}}\right)^{2}\right)^{1 / 3} .
$$

Here, $\mu_{i}$ and $E_{i}$ are Poisson's ratio and modulus of elasticity of pinion $i$ and gear $i$; $c_{\alpha}$ represents the parameter $\theta\left(\cos ^{-1}(B / A)\right)$, which can be interpolated through discrete data in the corresponding Table [21]. $A$ and $B$ are geometric parameters near the contact point of the tooth surface, which can be obtained by the following formulas:

$$
\begin{aligned}
& A=\frac{1}{2}\left(k_{\mathrm{I} 1}+k_{\mathrm{I} 2}+k_{\mathrm{II} 1}+k_{\mathrm{II} 2}\right) \\
& B=\frac{1}{2} \sqrt{\left(k_{\mathrm{I} 1}-k_{\mathrm{II} 1}\right)^{2}+\left(k_{\mathrm{I} 2}-k_{\mathrm{II} 2}\right)^{2}+2\left(k_{\mathrm{I} 1}-k_{\mathrm{II} 1}\right)\left(k_{\mathrm{I} 2}-k_{\mathrm{II} 2}\right) \cos 2 \phi} .
\end{aligned}
$$

Here, $k_{\mathrm{I} 1}$ and $k_{\mathrm{II} 1}$ are the first and second principal curvatures of the pinion tooth surface at the meshing point, respectively; $k_{\mathrm{II} 2}$ and $k_{\mathrm{I} 2}$ are the first and second principal curvatures of the large gear teeth at the meshing point, respectively; $\phi$ are the angles of the first main direction of the pinion tooth surface and the large gear tooth surface at the meshing point.

It is known from the above analysis that the relationship between the contact deformation $\delta_{3}(T)$ of the spiral bevel gear pair and the load $T$ can be expressed as $\delta_{3}(T(k))=$ $c T(k)^{2 / 3}$.

The relational expression of the integrated angular deformation $\Delta \varphi_{i j}\left[T_{i j}(k)\right]$ and torque $T_{i j}(k)$ of the gear pairs of the system can be expressed as

$$
\begin{aligned}
\Delta \varphi_{i j}\left(T_{i j}(k)\right) & =\delta_{1}(T(k))+\delta_{2}[T(k)]+\delta_{3}[T(k)] \\
& =\frac{T_{i j}(k)}{\left|T_{i j}(k)\right|}\left(a+b T_{i j}(k)+c T_{i j}(k)^{2 / 3}\right) .
\end{aligned}
$$

Here, $a, b$, and $c$ are constant terms in the formula, which are determined by the geometric parameters of the gear and the coordinates of the meshing position; $T_{i j}(k)(k=$ $1,2, \ldots, 5)$ is the torque of the $k$ th meshing position in a meshing cycle.

Based on the above traditional elastic mechanics analysis, the basic relationship between the tooth deformation and the transfer moment of the bevel gear is deduced. The actual calculation of the integrated angular deformation of the gear 


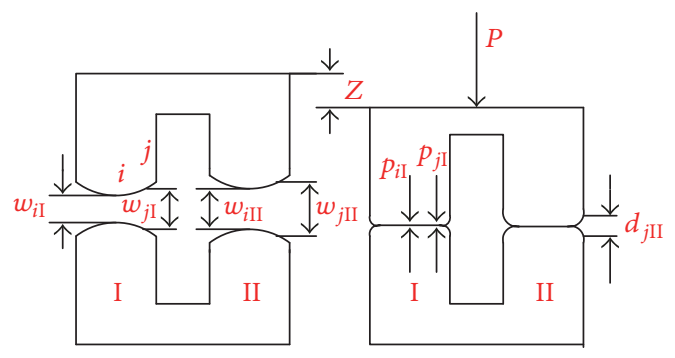

FIGURE 7: The model of the teeth geometric contact analysis under the action of a certain load $P$.

is obtained by the teeth geometric contact analysis simulation technology to ensure the accuracy of the calculation.

The model of the teeth geometric contact analysis is shown in Figure 7 under the action of a certain load [21]. The two pairs of teeth in contact with each other at a specific moment in the meshing cycle are denoted by I and II. The tooth surface curve is vertical along the relative principal direction in the normal plane. $i_{k}(k=\mathrm{I}, \mathrm{II})$ is the contact point; $j_{k}$ is a point along the relative principal direction.

Here, the tooth surface initial clearance $w$ of gear I and gear II is $[w]_{k}=[\delta]_{k}+[b]_{k}(k=\mathrm{I}, \mathrm{II}) .[\mathbf{w}]_{k}=\left[w_{1 k}, w_{2 k}, \ldots\right.$, $\left.w_{i k}, \ldots, w_{j k}, w_{n k}\right]^{\mathrm{T}},[\mathbf{b}]_{k}=\left[b_{1}, b_{2}, \ldots, b_{i}, \ldots, b_{n}\right]^{\mathrm{T}}$, and $[\boldsymbol{\delta}]_{k}=$ $[1,1, \ldots, 1, \ldots, 1]^{\mathrm{T}} ; n$ is the number of discrete points; $b_{j}$ is the tooth surface normal clearance $(j=1, \ldots, n) ; \delta$ is the geometric transmission error. $Z$ represents the direction of the displacement.

Under the action of load $P$, the gear tooth has elastic deformation, and the deformation coordination condition of the elastic deformation is as follows:

$$
\begin{gathered}
{[F]_{k}[p]_{k}+[w]_{k}=[Z]_{k}+[d]_{k}} \\
(k=\mathrm{I}, \mathrm{II})\left(\begin{array}{c}
{[p]_{k}=\left[p_{1 k}, p_{2 k}, \ldots, p_{i k}, \ldots, p_{j k}, p_{n k}\right]^{T}} \\
{[Z]_{k}=[1,1, \ldots, 1, \ldots, 1]^{T}} \\
{[d]_{k}=\left[d_{1 k}, d_{2 k}, \ldots, d_{i k}, \ldots, d_{j k}, d_{n k}\right]^{T}}
\end{array}\right) .
\end{gathered}
$$

$[F]_{k}$ is the normal flexibility coefficient matrix of the gear pair $k ; p_{j}(j=1,2, \ldots, n k)$ is the contact load supported at point $j$ of the tooth pair $k$. Apparently, the contact force $p_{j}(j=1,2, \ldots, n k)$ must satisfy the following conditions [21]:

$$
\sum_{j=1}^{n} p_{j \mathrm{I}}+\sum_{j=1}^{n} p_{j \mathrm{II}}=P
$$

where if $p_{j k}>0$, then $[d]_{j k}=0$; if $[p]_{j k}=0$, then $[d]_{j k}>0$.

$f, P$, and $w$ are known conditions. The contact forces $[p]_{j k}$, final tooth clearance $[d]_{j k}$, and tooth approach $[Z]$ are unknown. The known parameters $(f, P, w)$ and unknown parameters $(p, d, Z)$ constitute a nonlinear program model. According to the tooth approach $Z_{k}$, the following objective function is established:

$$
\text { Minimize }[p]^{T}\{[F][p]+[w]-[Z]\} .
$$

Equations (38) and (39) represent a constrained nonlinear programming problem, which is solved by the modified simplex method.

The objective function (40) forms a nonlinear programming model with functions (38) and (39) as constraint conditions:

$$
\begin{array}{ll}
\min & \sum_{j=1}^{2 n+1} X_{j}-[F][p]+[Z]+[d]+[X]=[w] \\
\text { s.t. } & {[e]^{T}[p]+X_{2 n+1}=P} \\
p_{j} \geq 0, d_{j} \geq 0, Z \geq 0, X_{j} \geq 0 ; p_{j}=0 \text { or } d_{j}=0,
\end{array}
$$

where $X_{j}(j=1,2, \ldots, 2 n+1)$ are the artificial variables, $[X]=\left[X_{1}, \ldots, X_{2 n}\right]^{\mathrm{T}} ;[e]$ of each element is equal to 1. The column vector $[p]$ is solved by the programming problem representing the discrete distribution of the contact load along the contact line that coincides with the relative principal direction.

Through the finite element calculation and the gear geometric contact simulation analysis program, when the gear pair is in the meshing position $k$, solving (36), the load transmission errors $\Delta \varphi_{i j}\left[0.1 T_{i j}(k)\right], \Delta \varphi_{i j}\left[0.5 T_{i j}(k)\right]$, and $\Delta \varphi_{i j}\left[0.9 T_{i j}(k)\right]$ are obtained. The results are brought into formula (23), and the coefficients $a, b$, and $c$ are obtained, and the function relation between the bearing deformation of the gear pair and the nominal load is obtained. The time-varying meshing stiffness of each gear pair is obtained. By replacing the results into formula (6), the excitation conditions of the time-varying meshing stiffness can be obtained as [22]

$$
K_{\mathrm{m} i j}(k)=\frac{T_{i j}(k)}{r_{b i}^{2} \cos a_{\mathrm{n}}} \frac{1}{\Delta \varphi_{i j}\left[T_{i j}(k)\right]} .
$$

The meshing stiffness reflects the comprehensive stiffness of each tooth pair involved in the meshing and can reflect the meshing elastic characteristics of the meshing position more directly. The comprehensive stiffness of the gear tooth obtained by this method has the same dimension and physical meaning as the comprehensive stiffness of the gear tooth in the ISO gear standard.

\section{Example Analysis}

Table 1 shows the main parameters of the power-split twostage five-branching planets gear train. Input power is $P=$ $208 \mathrm{~kW}$. Input speed is $1400 \mathrm{r} / \mathrm{min}$. The error of each length is $6 \mu \mathrm{m}$. The errors in the manufacturing and installation of the components are selected according to the position error of GB1182 1184-80 (National Standard of People's Republic of China). Here, the bending rigidity $K_{w}$ of spline shaft is $1.78 \times$ $10^{7} \mathrm{~N} \cdot \mathrm{m}^{-1}$ according to the mechanics calculation theory of cantilever beam. The bearing support stiffness of the sun gear $K_{\mathrm{S}}$ is $5.5 \times 10^{8} \mathrm{~N} \cdot \mathrm{m}^{-1}$, and the bearing support stiffness of ring gear ring $K_{\mathrm{r}}$ is $1.1 \times 10^{9} \mathrm{~N} \cdot \mathrm{m}^{-1}$ according to [23].

Figures $8(\mathrm{a})$ and $8(\mathrm{~b})$, respectively, show time-varying meshing stiffness of sun gear and I-stage planets gear and IIstage planets gear and ring gear meshing stiffness. Here, the 
TABLE 1: Main parameters of the two-stage five-branching planets gear train.

\begin{tabular}{lccccc}
\hline Name & Teeth number & Module $(\mathrm{mm})$ & Tooth width $(\mathrm{mm})$ & Helix angle $\left(^{\circ}\right)$ & Pressure angle $\left(^{\circ}\right)$ \\
\hline Sun gear & 24 & 4 & 70 & 10 & 20 \\
I-stage planets gear & 81 & 4 & 70 & 90 & 20 \\
II-stage planets gear & 31 & 4 & 90 & 8 & 20 \\
Ring gear & 99 & 4 & 90 & 20 \\
\hline
\end{tabular}

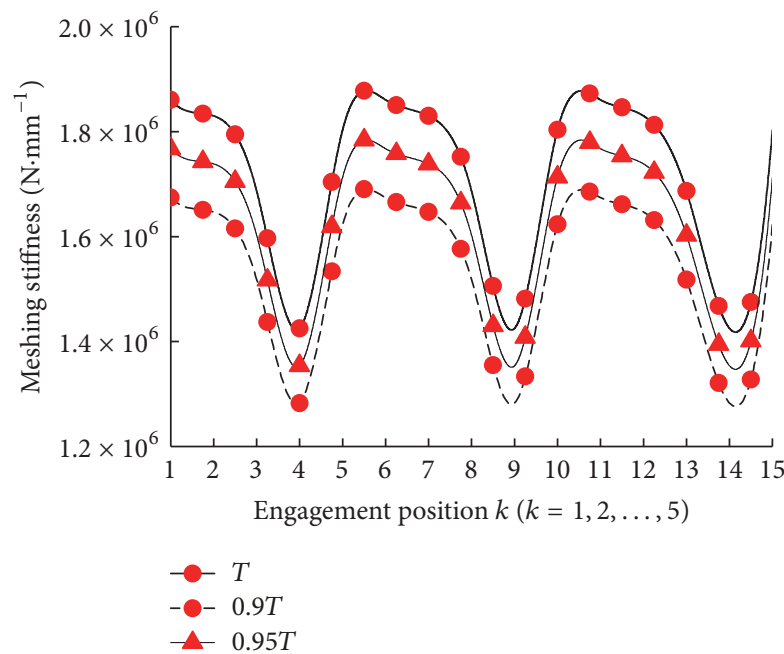

(a) Meshing stiffness of I-stage planets gear and sun gear

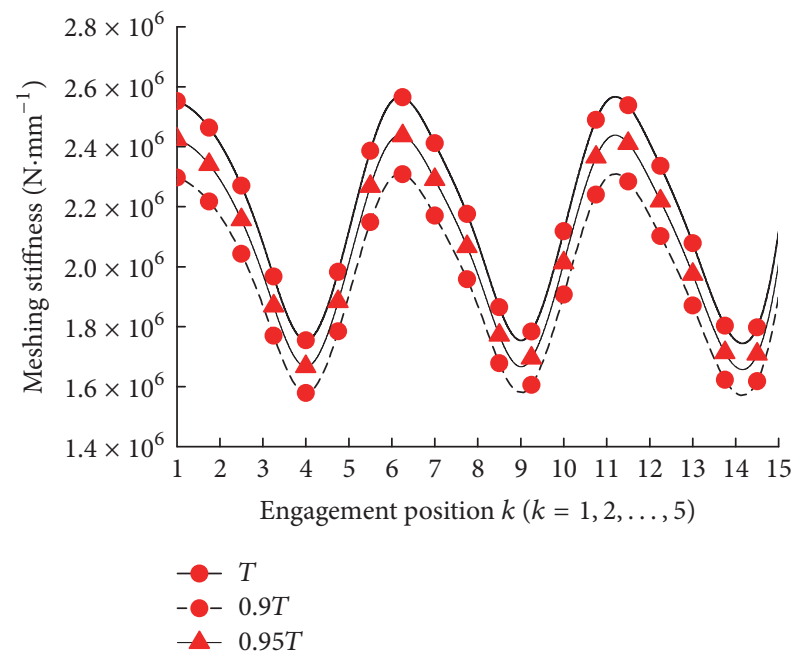

(b) Meshing stiffness of II-stage planets gear and ring gear

FIGURE 8: Meshing stiffness of each gear pair in the two-stage five-branching planets gear train.

three curves are the meshing stiffness curves under the loads of $T, 0.9 T$, and $0.95 T$, respectively. The meshing stiffness fluctuation range of sun gear and I-stage planets gear is (1.28 $\left.\times 10^{6} \sim 1.87 \times 10^{6}\right) \mathrm{N} \cdot \mathrm{m}^{-1}$. The meshing stiffness fluctuation range of II-stage planets gear and ring gear is $\left(1.57 \times 10^{6} \sim\right.$ $\left.2.58 \times 10^{6}\right) \mathrm{N} \cdot \mathrm{m}^{-1}$. Due to the different meshing stiffness of each meshing position of the tooth surface, the load-sharing coefficient of different meshing positions will be changed slightly.

5.1. Influence of Basic Parameters on Load-Sharing Characteristics. Under these parameters, the load-sharing coefficient of the planets gears is shown in Figure 9.

From Figure 9, we can see that the load-sharing coefficient of the planets gear is changed according to a certain period. The load-sharing coefficients of planets gear are 1.023, 1.036, $1.028,1.030$, and 1.025. Therefore, the load-sharing coefficient of the system is $J=1.036$.

The torque $T_{\mathrm{sp} I i}$ of I-stage planets gear and the torque $T_{\text {spII } i}$ of II-stage planets gear are changed as shown in Figures 10 (a) and 10(b).

The calculation results of the load-sharing coefficient are shown in Table 2, with the assembly error $A$ s of the sun gear, the assembly errors $A_{\mathrm{pI}}$ and $A_{\mathrm{pII}}$ of the planets gear, and the assembly error $A \mathrm{r}$ of the ring gear independent effect.

The calculation results of the load-sharing coefficient are shown in Figure 11, with the eccentric error Es of the sun gear, the eccentric errors $E_{\mathrm{pI}}$ and $E_{\mathrm{pII}}$ of the planets gear, and the eccentric error $E r$ of the ring gear independent effect.

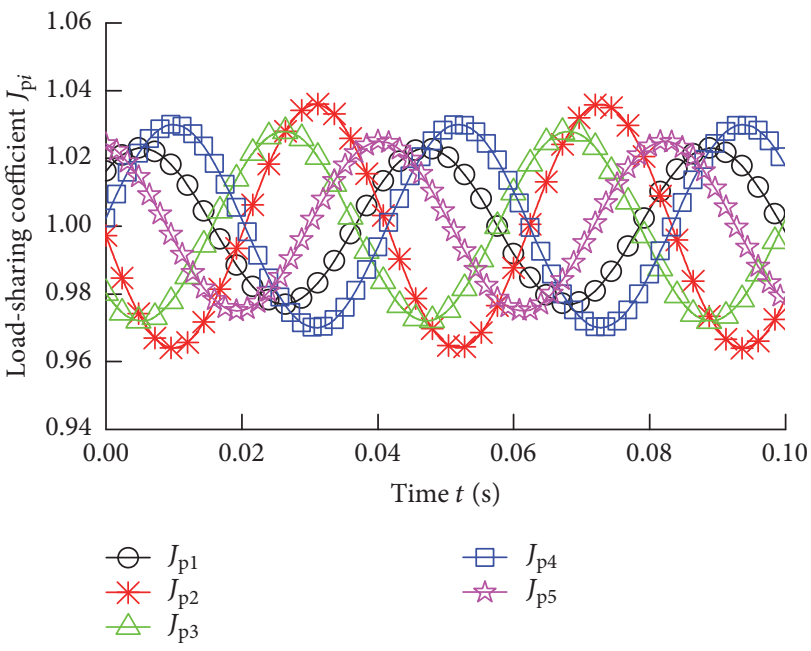

FIGURE 9: Effect of the common error of planets gear on load-sharing coefficient.

It can be seen from the calculation results shown in Figure 11 that, for manufacturing and installation errors, when the error values are the same, the error of the ring gear is the highest, the error of the II-stage planets gear is middle, and the error of the sun gear is the lowest.

5.2. Effect of the Error on the Load-Sharing Coefficient. The relationship between the load-sharing coefficient and the eccentricity error $E_{\mathrm{s}}$ of the sun gear and the eccentric error 


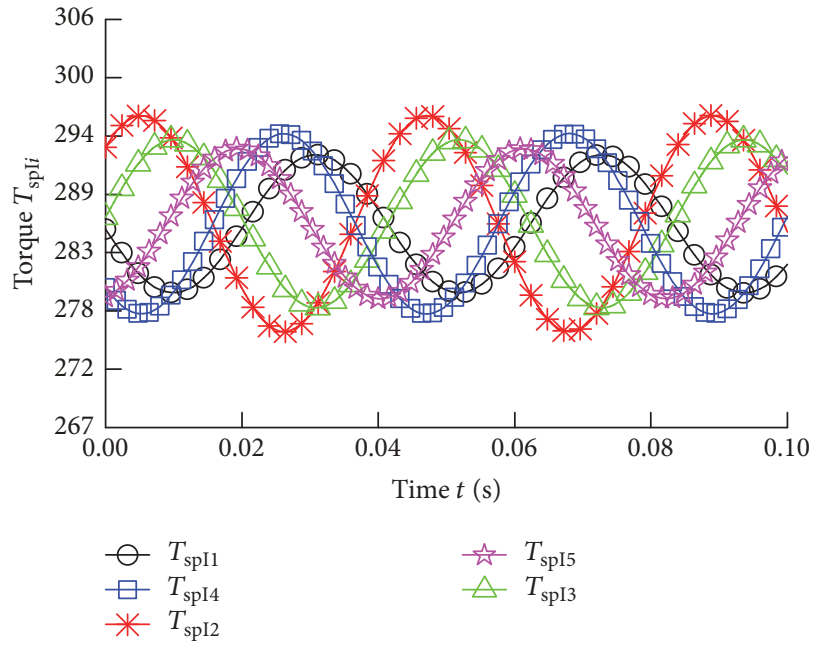

(a) Torque $T_{\text {spIi }}$ of I-stage planets gear

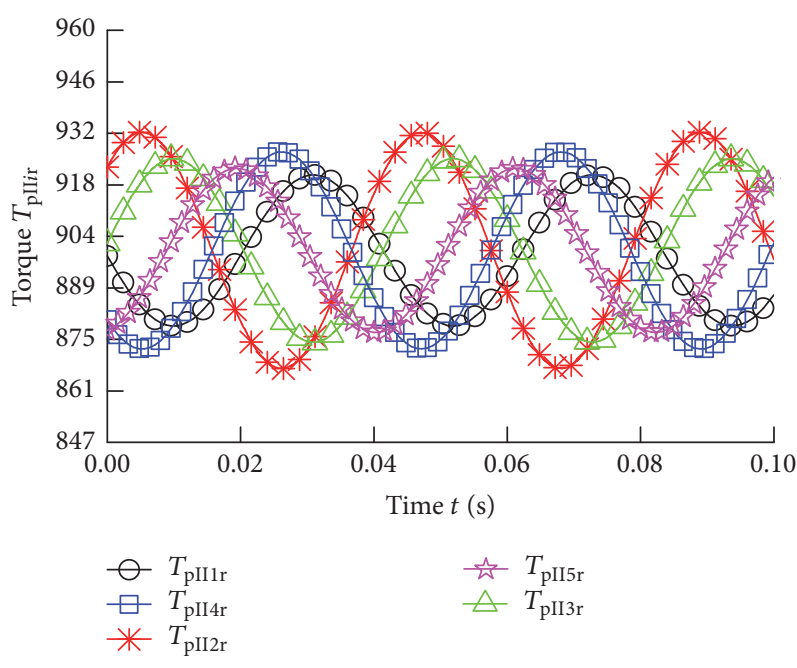

(b) Torque $T_{\mathrm{spII} i}$ of II-stage planets gear

FIgURE 10: Torque force of the I-stage and II-stage planets gears.

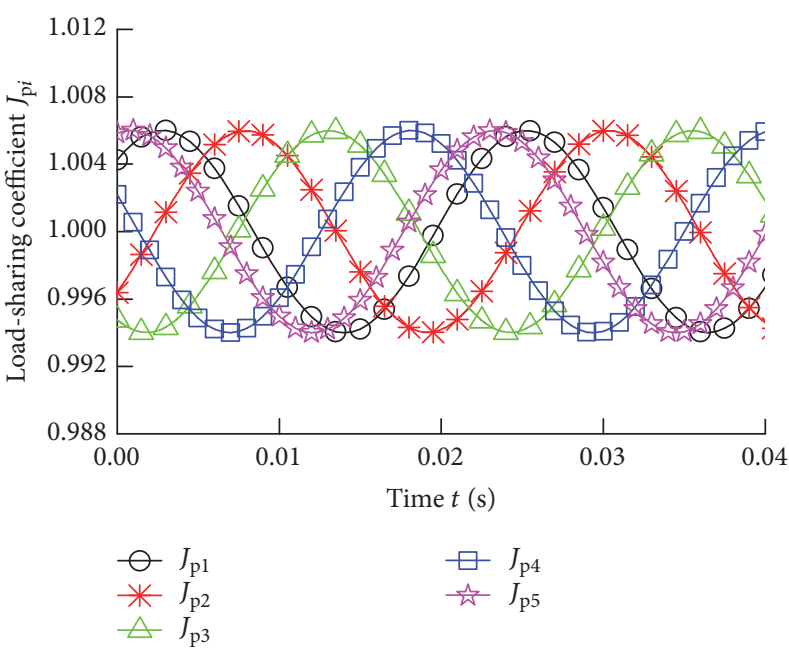

(a) Eccentric error Es of sun gear

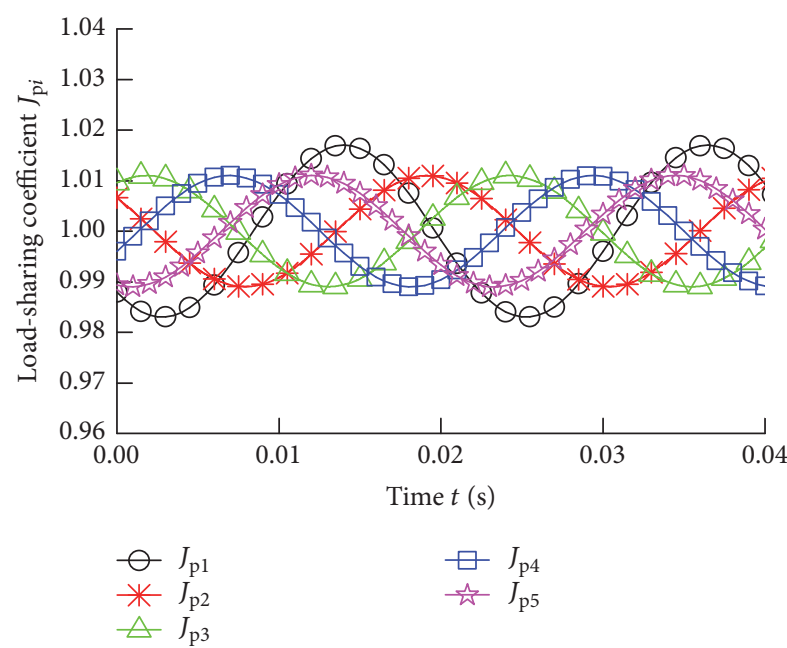

(c) Eccentric error $E_{\mathrm{pII}}$ of II-stage planets gear

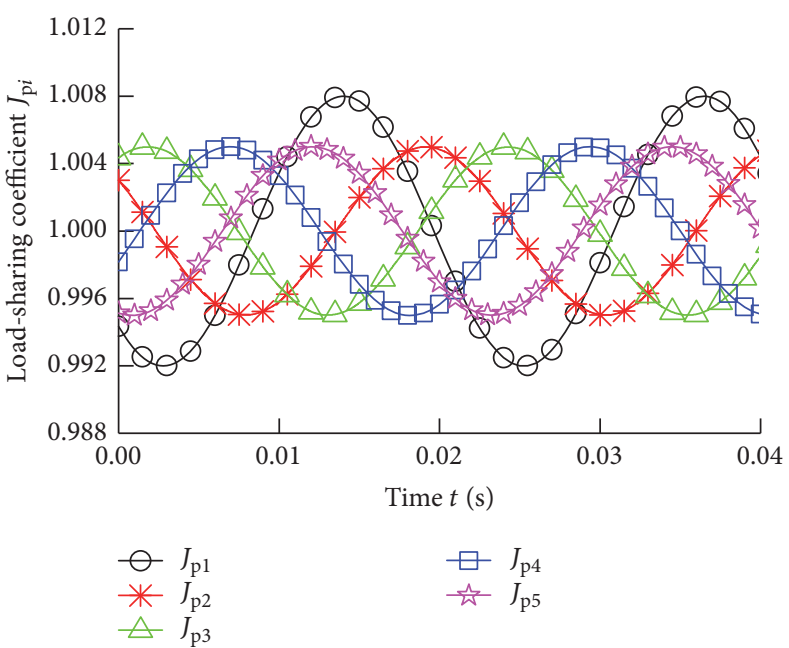

(b) Eccentric error $E_{\mathrm{pI}}$ of I-stage planets gear

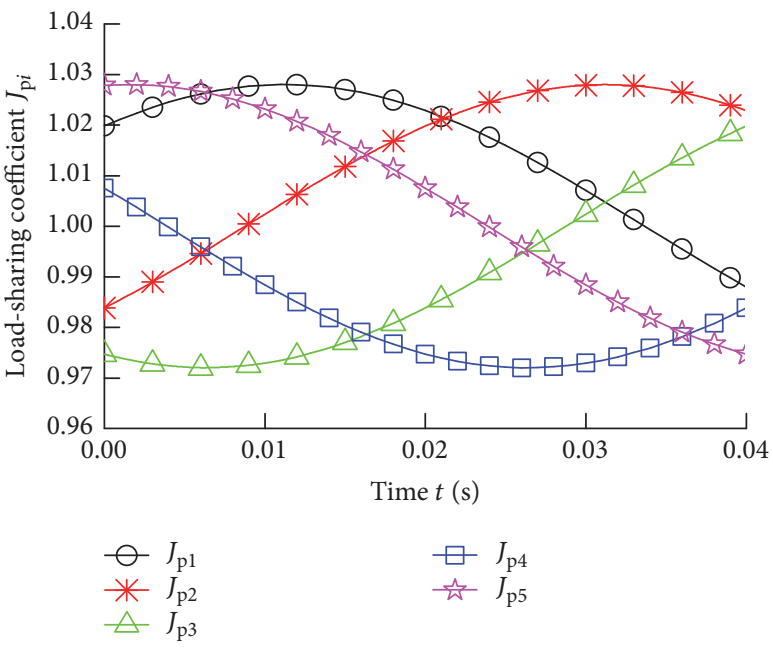

(d) Eccentric error Es of ring gear

FIGURE 11: Load-sharing coefficient changed with the eccentricity error independent effect. 
TABLE 2: Load-sharing coefficient when assembling error independent effect.

\begin{tabular}{lcccc}
\hline Load-sharing coefficient & $A_{\mathrm{s}}(6 \mu \mathrm{m})$ & $A_{\mathrm{pI} 1}(6 \mu \mathrm{m})$ & $A_{\mathrm{pII} 1}(6 \mu \mathrm{m})$ & 1.016 \\
\hline$J_{\mathrm{p} 1}$ & 1.004 & 1.006 & 0.983 & $A_{\mathrm{r}}(6 \mu \mathrm{m})$ \\
$J_{\mathrm{pI} 2}$ & 0.996 & 0.995 & 0.992 & 1.012 \\
$J_{\mathrm{pI} 3}$ & 0.997 & 0.994 & 1.012 & 0.991 \\
$J_{\mathrm{pI} 4}$ & 1.006 & 1.008 & 1.013 & 1.018 \\
$J_{\mathrm{p} 15}$ & 1.003 & 1.005 & 1.016 & 0.985 \\
$J$ & 1.006 & 1.008 & 1.018 \\
\hline
\end{tabular}

$E_{\mathrm{r}}$ of the ring gear is shown in Figure 12(a). The relationship between the load-sharing coefficient and the eccentricity error $E_{\mathrm{pI} i}$ is shown in Figure 12(b). The relationship between the load-sharing coefficient and the eccentricity error $E_{\mathrm{pII} i}$ of the II-stage planets gear is shown in Figure 12(c). The relationship between the load-sharing coefficient and the assembly error $A_{\mathrm{s}}$ of the sun gear and the eccentric error $A_{\mathrm{r}}$ of the ring gear is shown in Figure 12(d). The relationship between the load-sharing coefficient and the assembly error $A_{\mathrm{pI} i}$ of the I-stage planets gear is shown in Figure 12(e). The relationship between the load-sharing coefficient and the assembly error $A_{\mathrm{pII} i}$ of the II-stage planets gear is shown in Figure 12(f).

It can be seen from Figure 12 that, with the increase of the eccentricity error and assembly error of the sun gear and the ring gear and the I-stage and II-stage planets gear, the loadsharing coefficient gradually increases. The influence of the II-stage error on load-sharing characteristic is greater than the effect of the I-stage error.

5.3. Influence of the Sun Gear and Ring Gear Floating on LoadSharing Characteristics. Figure 13 shows the variation of the load-sharing coefficient. It can be seen from Figure 13 that when the sun gear and ring gear are not floating, the loadsharing coefficient is 1.058 , and the volatility is large. When the ring gear is floating and the sun gear is fixed, the loadsharing coefficient is 1.023 . When the sun gear and ring gear are floating, the load-sharing coefficient is 1.008. At this time, the system has good load-sharing characteristics.

Figure 14 shows the variation of the load-sharing coefficient with the variation of the spline space. Figure 15 shows the floating trajectory of the sun gear and ring gear.

When the spine clearance is $0.00 \mathrm{~mm}$, the floating sun gear will completely be determined by the bending rigidity of input shaft; here, the sun gear is supported by an elastic support. Next, the spline clearance gradually increases, and the load-sharing characteristics will be better and better. Finally, the load-sharing coefficient is obtained. At the same time, due to the impact of friction, the load-sharing coefficient of the system is 1.013 . It can be seen under the condition of constant error that the system load-sharing coefficient decreases with the increase of spline clearance. When the gap is large enough, the system load-sharing characteristics will achieve an ideal load effect. From the above analysis, we can see that the basic components floating can be good to improve the load-sharing characteristics of the whole system.

\section{Experimental Verification}

In order to verify the correctness of the theoretical analysis of this paper, the static load-sharing characteristics test of the two-stage five-branching planets gear train is carried out. The test method for the load-sharing effect of the two-stage fivebranching planets gear train is usually used to paste strain gauge at the corresponding position. By measuring the strain, the load of the planets gears is reflected. However, if the strain gauge is placed on the teeth of the gear, because the space of the strain gauges is smaller, it is difficult to paste the strain gauge. At this time, we need to fabricate the microelectric appliance and the wireless launcher to meet the requirement of the small structure, and the cost is too expensive. If the strain gauge is pasted on the motionless body, because the body's rigidity is high, load transfer is small, strain variation is small, and the location of the paste strain gauge cannot be guaranteed to be identical, making an inaccurate test plan further increases the overall error factor. Therefore, there are many limitations in the test method of resistance strain gauge, and it is not ideal.

In this paper, taking into account the fact that the high speed planets gear transmission is a helical gear, therefore, it can be used to measure the axial force to determine the loaded distribution between each planetary gear. The five helical gears will produce a certain axial force in the course of the transfer load. The five planets gear shafts are transmitted to a special precision mechanical sensor through a torsion bar. The axial force generated by five planets gears in high speed operation is measured by a precision mechanical sensor. The load-sharing coefficient of the planets gear reducer can be obtained by the above method. It can evaluate the effect of load-sharing characteristics of planets gear system. The axial forces of the five helical gears are $F_{P 1}, F_{P 2}, F_{P 3}, F_{P 4}$, and $F_{P 5}$, respectively. Therefore, the load-sharing coefficient $J$ of the planets gear system can be obtained by

$$
J=\frac{F_{P \max }}{F_{P 1}+F_{P 2}+F_{P 3}+F_{P 4}+F_{P 5}} .
$$

In formula (42), $F_{P \max }$ is the maximum value of axial force of five planets gears.

In the experiment, according to the actual working state of the planets reducer, the load is allocated into five parts, and each load state is measured five times, and the average value is taken as the load-sharing coefficient under the load. The test piece is installed in the reducer in the tester. The measuring equipment uses the closed principle of mechanical power flow. Due to the fact that the drive ratio of the closed 


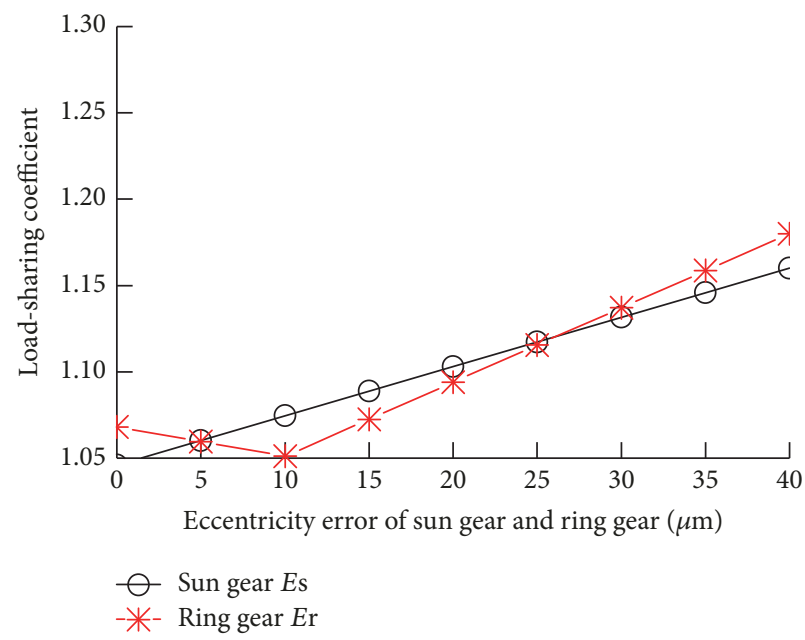

(a) Eccentricity error of the sun gear and the ring gear

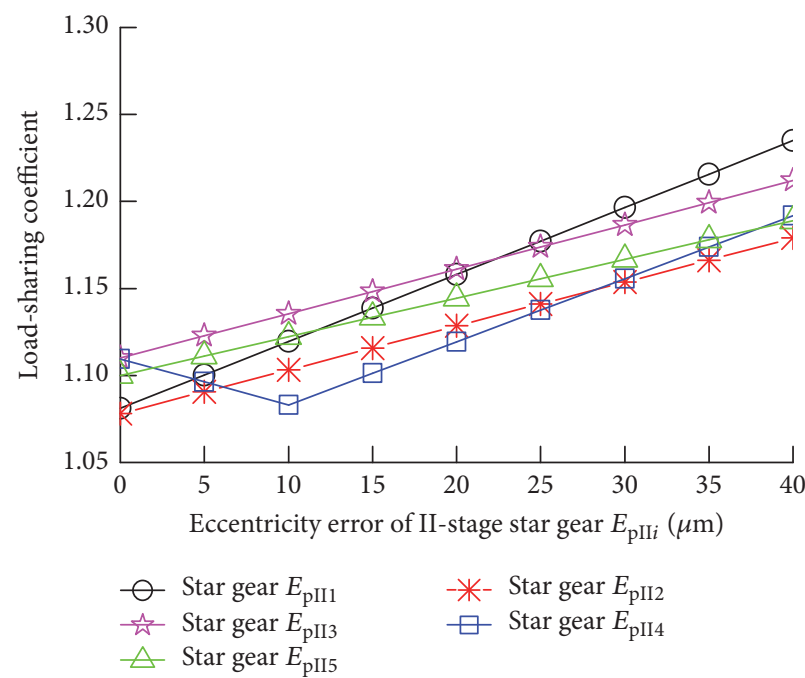

(c) Load-sharing coefficient changed with the eccentricity error of the II-stage planets gear

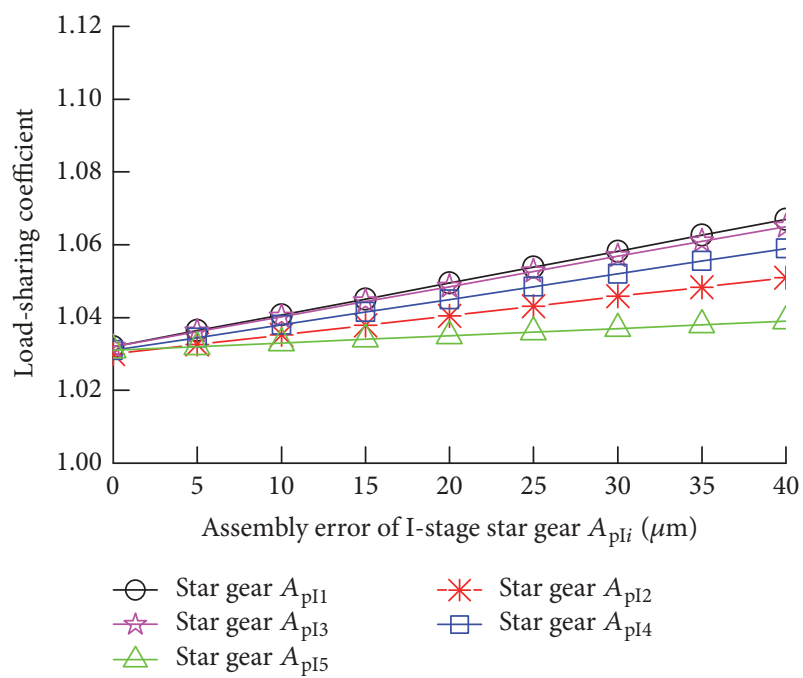

(e) Load-sharing coefficient changed with the assembly error of the Istage planets gear

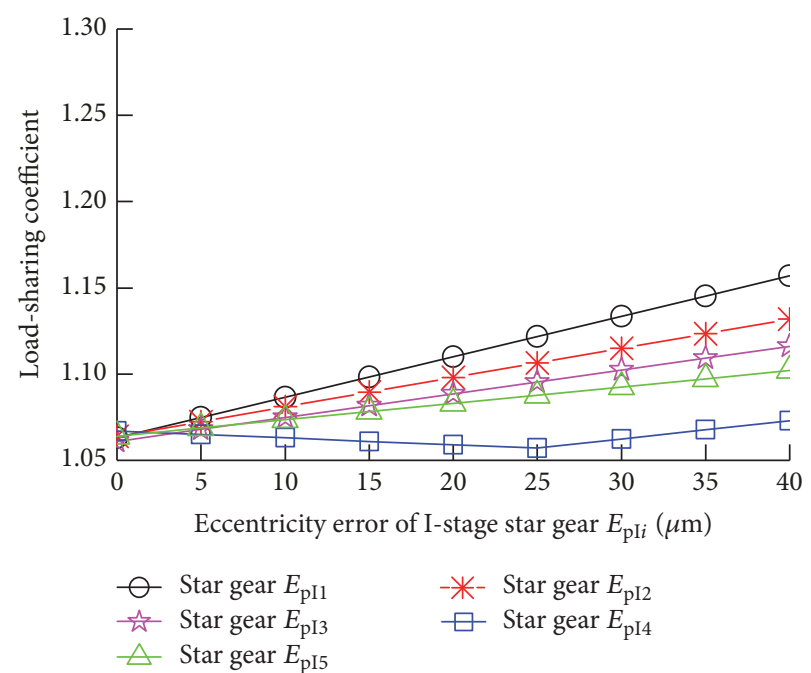

(b) Load-sharing coefficient changed with the eccentricity error of the I-stage planets gear

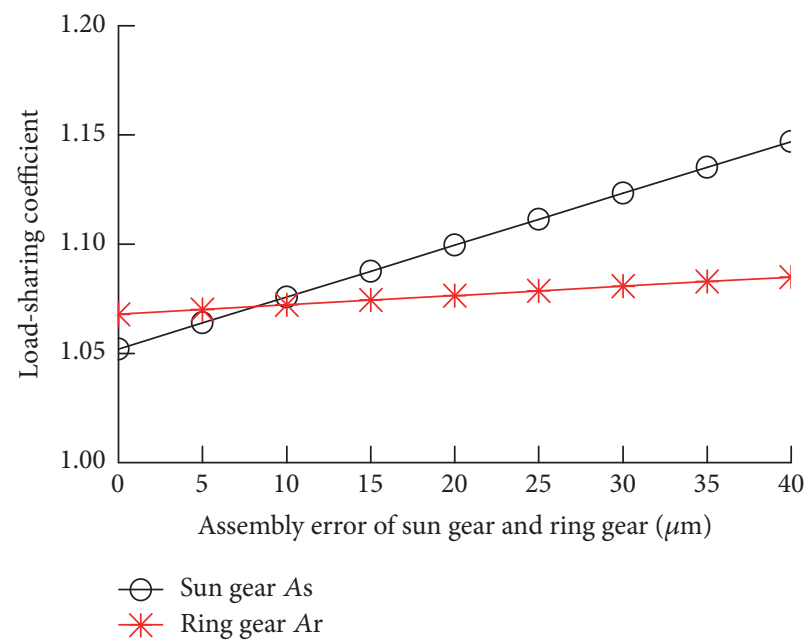

(d) Load-sharing coefficient changed with the assembly error of the sun gear and the ring gear

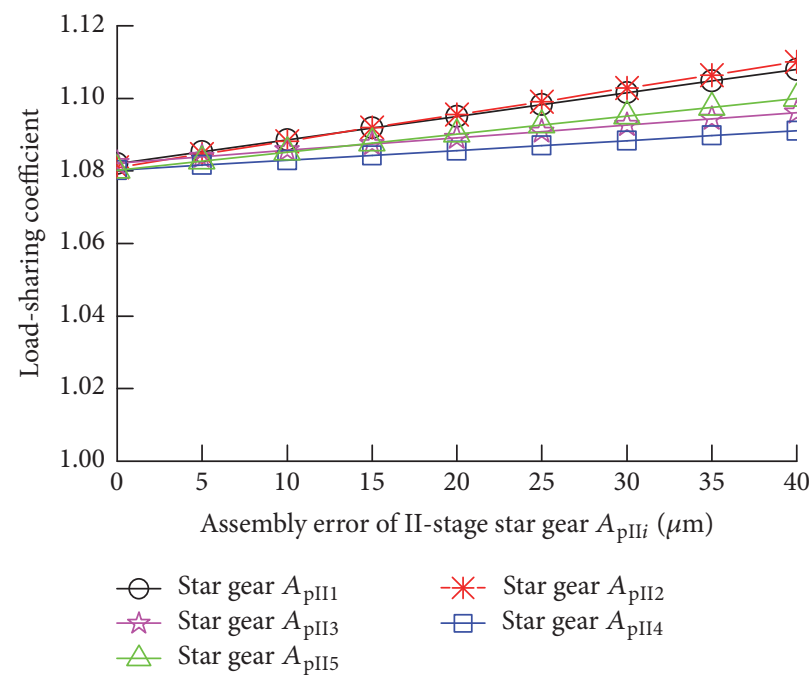

(f) Load-sharing coefficient changed with the assembly error of the IIstage planets gear

FIGURE 12: Load-sharing coefficient changed with the eccentricity error and assembly error. 
TABLE 3: Load-sharing coefficient under different loads.

\begin{tabular}{|c|c|c|c|c|c|c|c|c|}
\hline Input torque $T_{\text {in }}(\mathrm{N} \cdot \mathrm{m})\left(T_{\text {in }}=1419 \mathrm{~N} \cdot \mathrm{m}\right)$ & $20 \%$ & $40 \%$ & $60 \%$ & $80 \%$ & $100 \%$ & $120 \%$ & $140 \%$ & $160 \%$ \\
\hline Test load-sharing coefficient (average value) & 1.141 & 1.124 & 1.112 & 1.106 & 1.082 & 1.075 & 1.066 & 1.062 \\
\hline Theoretically calculated load-sharing coefficient & 1.071 & 1.062 & 1.054 & 1.046 & 1.038 & 1.030 & 1.022 & 1.014 \\
\hline
\end{tabular}

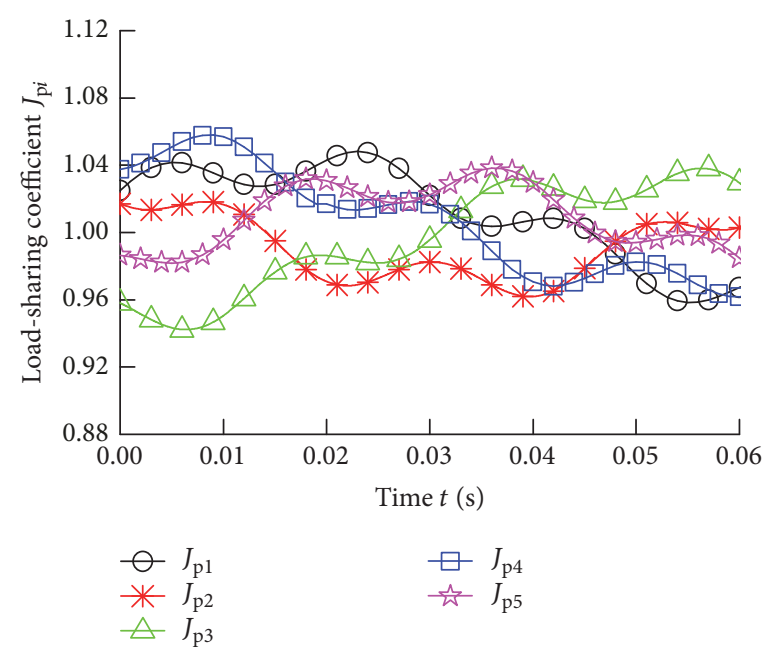

(a) Sun gear and ring gear without floating

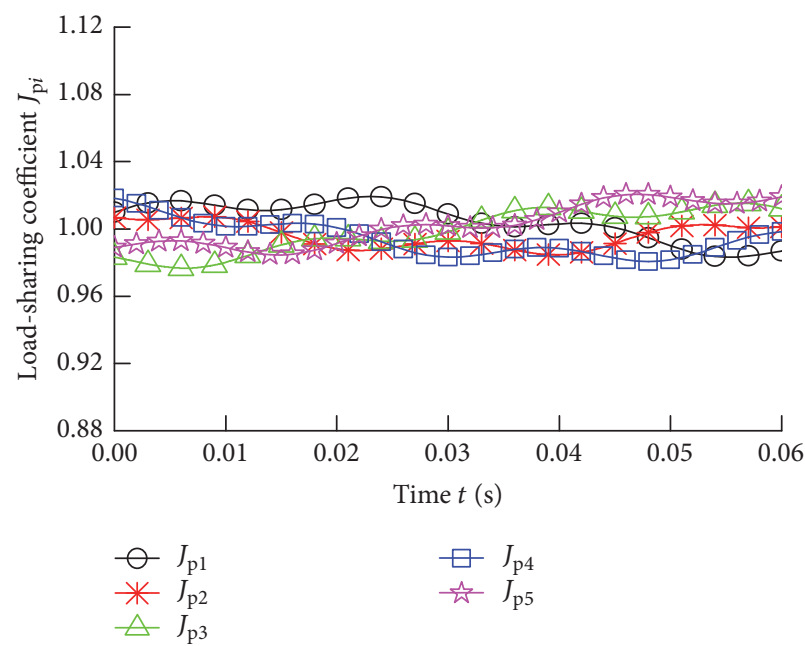

(b) Ring gear with floating

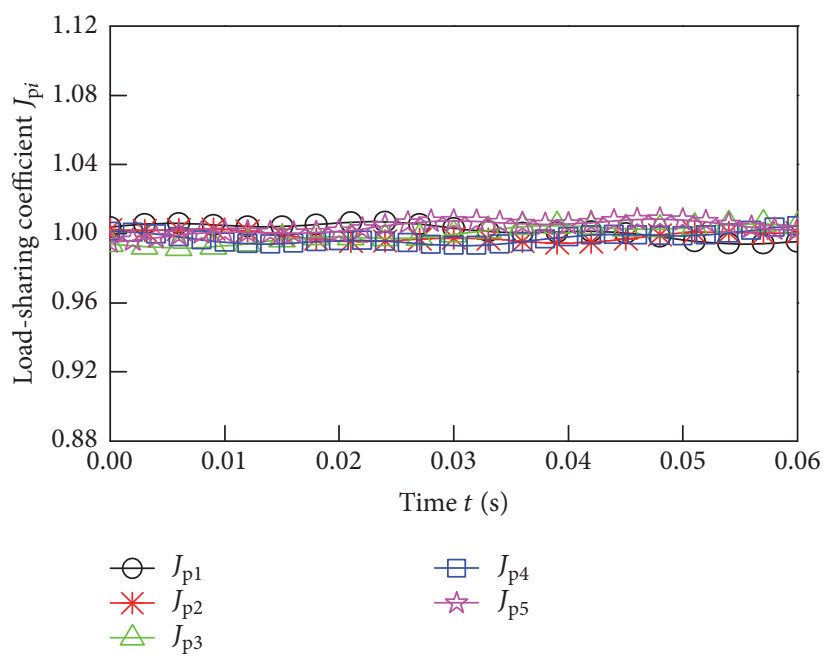

(c) Sun gear and ring gear with floating

FIGURE 13: Influence of sun gear and ring floating on the load-sharing characteristic.

loop required by this tester is equal to 1 , in order to fulfill these requirements, the input terminal of two planets gear deceleration device is connected. Along the direction of the power flow, one of the reducers plays the role of the increasing speed, and the other plays the role of decreasing speed. Figure 16 is a schematic diagram of the experimental principle.

As can be seen from Figure 16, the whole testbed consists of five parts: power source, test gearbox, measuring system, and accompanying test gearbox. The main test gearbox and the accompanying test gearbox are "back-to-back" installed. Among them, the power is provided by the electrical motor, and the speed is adjusted by the frequency converter. The main test gearbox is an independent planets shaped gearbox. The measuring system consists of two torque sensors and their display instruments. The accompanying test gearbox is another independent planets gearbox.

After the installation of the testbed was completed and the coaxiality of the system was completed, the load-sharing characteristics of the system were tested. First, the system is electrified and then adjusted to zero in the static state. After finishing zero adjustment, the output frequency and load torque of the motor are adjusted, and the load-sharing characteristic test is carried out.

The comparison between theoretical calculation results and experimental results is shown in Table 3. Here, the value 


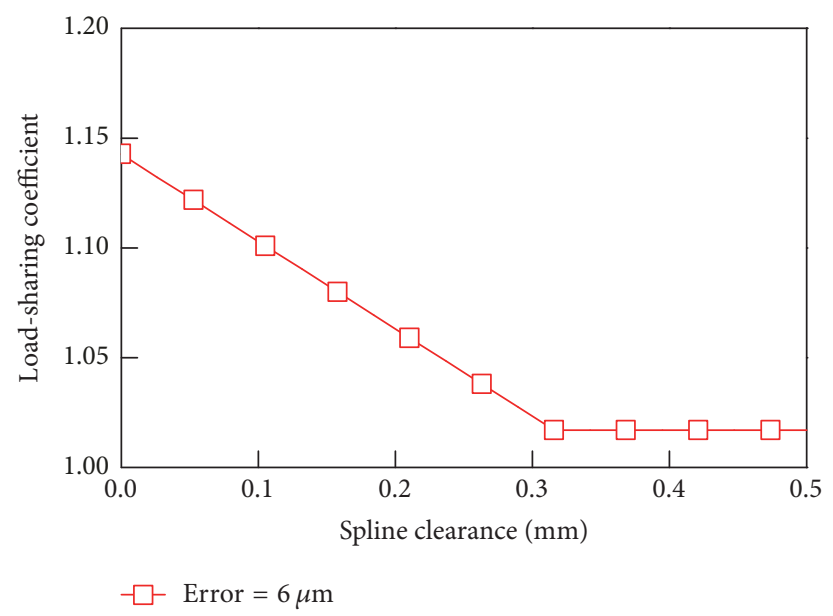

FIGURE 14: Load-sharing coefficient changed with the effect of spline clearance.

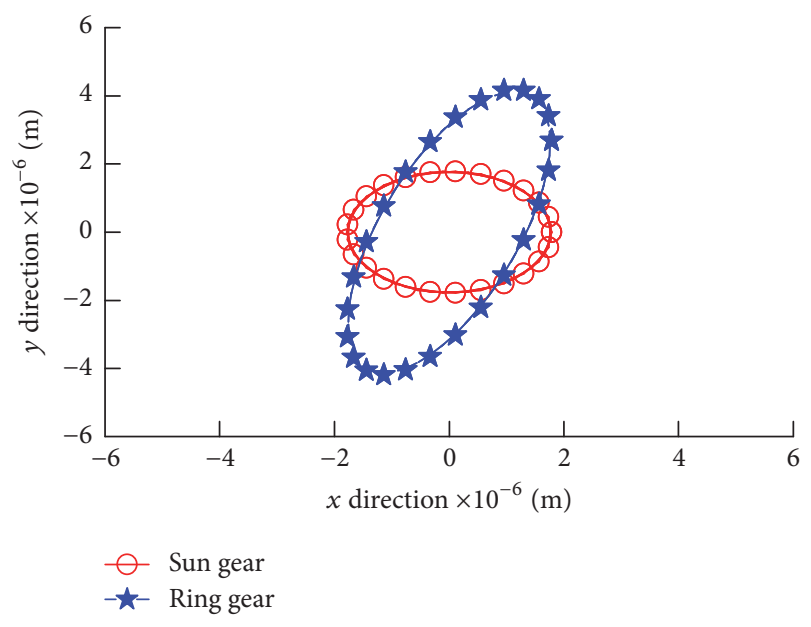

FIGURE 15: Floating orbit of the sun gear and ring gear.

of the input speed is constant; only the value of the input power is changed from $20 \%$ to $160 \%$.

As can be seen from Table 3, the load-sharing coefficient obtained by the test is $15 \%$ higher than that obtained by the theoretical calculation. The theoretical calculation value is the data obtained under ideal condition. Actually, due to the factors of processing and assembly and heat treatment, the actual situation and theoretical state are different. And there are many errors in the test system, so the experimental value and the calculated value are different. However, the experimental results are in line with the range of the load-sharing coefficient 1.1 1.5 recommended in the general project.

Figure 17 shows a diagram of the curve of the loadsharing coefficient varying with the input torque $T_{\text {in }}$. The load-sharing coefficient decreases with the increase of torque, and the experimental data and the theoretical calculation data have a good consistency. Figure 18 shows a graph of the change of the load-sharing coefficient with the input speed $n$, and the input speed changes from $20 \%$ of the given value to $200 \%$. The load-sharing coefficient increases with the increase of the input speed, indicating that when the speed of the system gets higher, the performance of the load-sharing is reduced. When the speed changes from $1120 \mathrm{r} / \mathrm{min}$ to $2240 \mathrm{r} / \mathrm{min}$, the change of the load-sharing coefficient is more obvious, from 1.062 to 1.15 . After the speed becomes more than $2240 \mathrm{r} / \mathrm{min}$, the change of the load-sharing coefficient tends to be stable. The theoretical calculation results show that the load-sharing coefficient is changed from 1.029 to 1.067 , and the overall change is relatively stable. This is because the values given in numerical calculation are all ideal values, and the experimental results are more influenced by external factors.

A calculation model for calculating the load of two-stage four-branching planets train is proposed in [2]. The loadsharing calculation model proposed in this paper is quite different from the calculation model of [2]. The load-sharing calculation model proposed in this paper uses the loaded tooth contact analysis, which can accurately calculate the time-varying meshing stiffness of each pair of gears, and it can more accurately reflect the influence of each meshing position of the gear pair on the load-sharing performance of the system. The two-stage four-branching planets train of [2] is analyzed and studied using the load-sharing calculation model mentioned in this paper. The comparison and analysis results are shown in Figure 19. Because the experiment process is different and the analysis of the system structure is different, the experimental results do not have comparability. The theoretical calculation results of load-sharing coefficient in this paper are compared with the experimental and theoretical results of [2]. It can be seen from the comparison that the results of the calculation in this paper have a good agreement with the calculation results of [2].

\section{Conclusions}

(1) The solution of the large complex gear transmission system is simplified by the deformation coordination condition. The errors of various components in the deformation coordination condition can be superimposed or offset. It can better reflect the 


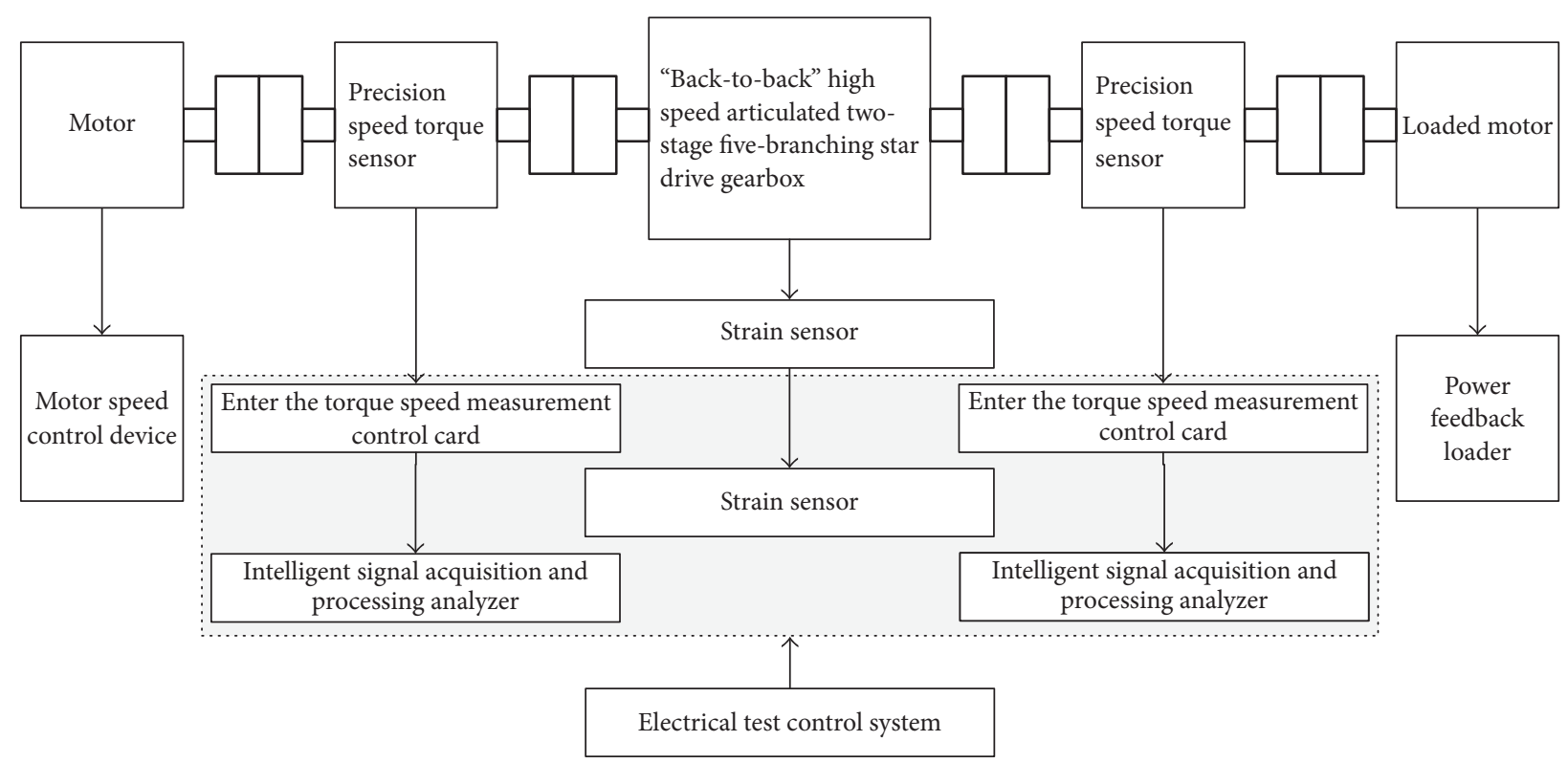

FIGURE 16: Schematic diagram of the experimental principle.

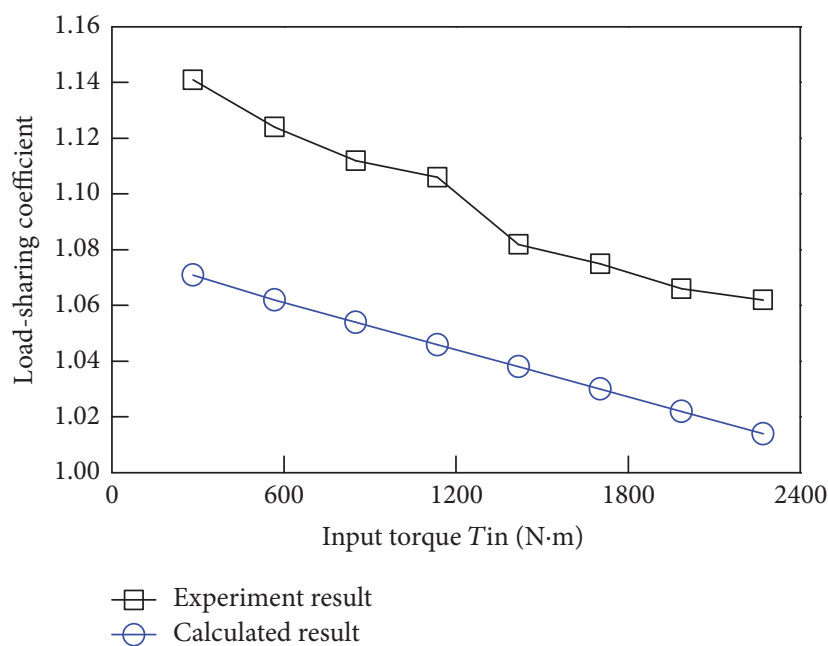

FIGURE 17: Relationship between input torque and load-sharing coefficient.

load-sharing characteristics of the whole system. It essentially reflects the load-sharing process caused by deformation. The deformation coordination condition is favorable to the overall design and analysis of the system, which can be applied in the gear transmission system with the power-split closed-loop characteristics.

(2) The eccentric error and the installation error of the various components have an effect on the load characteristics of the system. Moreover, the effects of errors are cumulative, and the error distribution of the components in stage II should be paid more attention. The main cause of the unbalanced load distribution of the planets gear transmission system is inconsistent

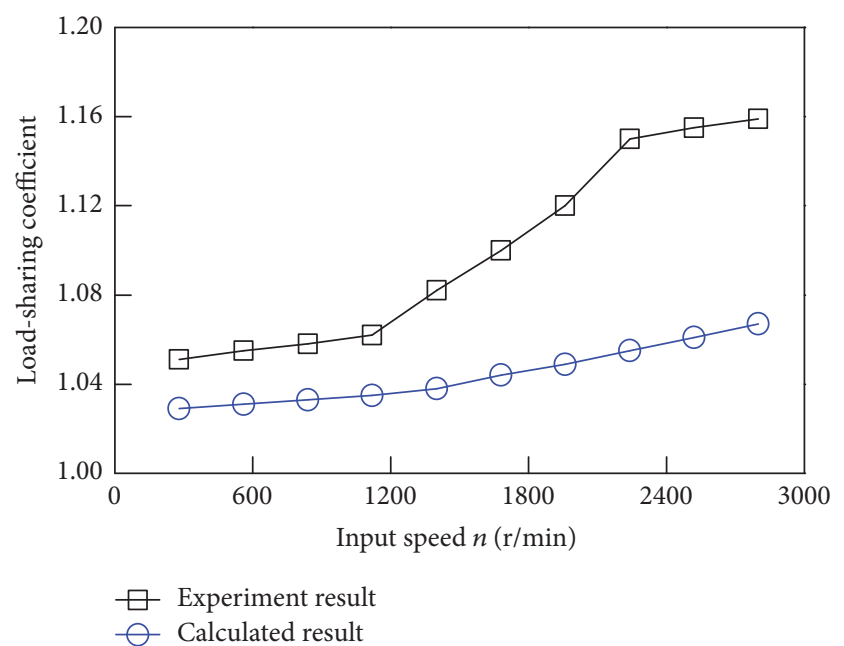

FIgURE 18: Relationship between input speed and load-sharing coefficient.

with the manufacturing error and the installation error. The floating of basic components is beneficial to the load-sharing among the planets. The spline space is a mechanism to reduce the block effect of floating of the basic components. However, the design of the gap does not follow the bigger the better rule, because the large gap will make the planets gear system in the work process produce serious vibration and impact.

(3) Load-sharing test was carried out under different rotating speeds. The experimental data were processed and were consistent with the theoretical calculation data. The correctness of theoretical analysis was verified. 


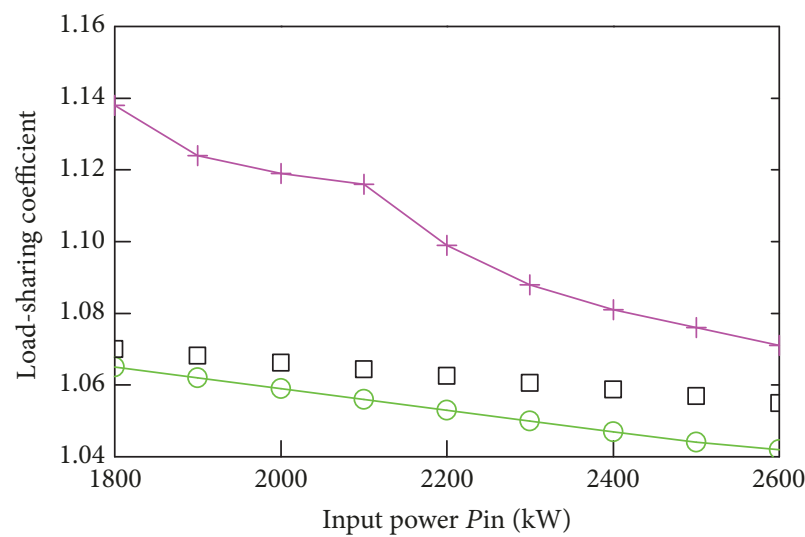

- Calculated results of [2]

Experiment results of [2]

Calculated results of this paper

(a) Relationship between input torque and load-sharing coefficient

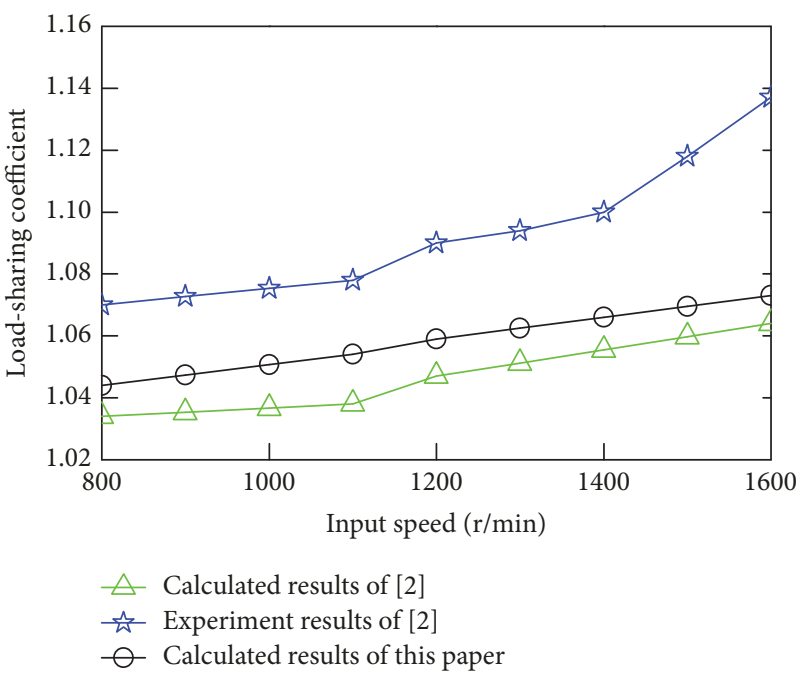

(b) Relationship between input speed and load-sharing coefficient

FIGURE 19: The comparison and analysis of the model proposed in this paper and the model proposed by [2].

\section{Conflicts of Interest}

The authors declare that there are no conflicts of interest regarding the publication of this paper.

\section{Acknowledgments}

This study was supported by the National Natural Science Foundation of China (51705390, 51375384), Xi'an Science and Technology Plan Project 2017075CG/RC038 (XAGY008), Xi'an Technological University Research and Innovation Team Construction Program, and Shaanxi Provincial Key Laboratory Project of Science and Technology Innovation (2014SZS20-K04).

\section{References}

[1] A. Kahraman, "Load sharing characteristics of planetary transmissions," Mechanism and Machine Theory, vol. 29, no. 8, pp. 1151-1165, 1994.

[2] S. Mo, Y. Zhang, and Q. Wu, "Research on multiple-split load sharing of two-stage star gearing system in consideration of displacement compatibility," Mechanism and Machine Theory, vol. 88, pp. 1-15, 2015.

[3] M. Li, L. Xie, and L. Ding, "Load sharing analysis and reliability prediction for planetary gear train of helicopter," Mechanism and Machine Theory, vol. 115, pp. 97-113, 2017.

[4] H. Xu, T. Xu, and Y. Huang, "Analysis of load sharing of planetary gear train considering the flexibility of planet carrier," Journal of Mechanical Transmission, vol. 40, pp. 107-111, 2016 (Chinese).

[5] Z. M. Q. Li, W. Ye, L. L. Zhang et al., "Effect predictions of star pinion geometry phase adjustments on dynamic load sharing behaviors of differential face gear trains," Journal of Vibroengineering, vol. 18, no. 1, pp. 81-92, 2016.

[6] D.-P. Sheng, R.-P. Zhu, G.-H. Jin, F.-X. Lu, and H.-Y. Bao, "Dynamic load sharing behavior of transverse-torsional coupled planetary gear train with multiple clearances," Journal of Central South University, vol. 22, no. 7, pp. 2521-2532, 2015.
[7] Y.-J. Park, J.-G. Kim, G.-H. Lee, and S. B. Shim, "Load sharing and distributed on the gear flank of wind turbine planetary gearbox," Journal of Mechanical Science and Technology, vol. 29, no. 1, pp. 309-316, 2015.

[8] J.-G. Kim, Y.-J. Park, G.-H. Lee, and J.-H. Kim, "An experimental study on the effect of carrier pinhole position errors on planet gear load sharing," International Journal of Precision Engineering and Manufacturing, vol. 17, no. 10, pp. 1305-1312, 2016.

[9] J. G. Kim, Y. J. Park, G. H. Lee, Y. Kim, J. Oh, and J. Kim, "Effect analysis of carrier pinhole position error on the load sharing and load distribution of a planet gear," Journal of the Korean Society of Manufacturing Process Engineers, vol. 15, no. 5, pp. 6672, 2016.

[10] M. Iglesias, A. F. D. Rincón, A. M. De-Juan, P. Garcia, A. Diez, and F. Viadero, "Planetary gear profile modification design based on load sharing modelling," Chinese Journal of Mechanical Engineering, vol. 28, no. 4, pp. 810-820, 2015.

[11] J. Wang, Y. Wang, and Z. Huo, "Load sharing behavior and dynamic equations for planetary gear train transmission of wind turbine gearboxes," Acta Energiae Solaris Sinica, vol. 36, no. 1, pp. 26-32, 2015.

[12] V. Spitas, G. A. Papadopoulos, C. Spitas, and T. Costopoulos, "Experimental investigation of load sharing in multiple gear tooth contact using the stress-optical method of caustics," Strain Journal, vol. 47, supplement 1, pp. e227-e233, 2011.

[13] L. Pan, R. Zhu, and G. Jin, "Load sharing characteristics of single-input gear split torque transmission based on synchronous angle," Zhongnan Daxue Xuebao, vol. 48, no. 1, pp. 47-53, 2017 (Chinese).

[14] H. Zhang, S. Wu, and Z. Peng, "A nonlinear dynamic model for analysis of the combined influences of nonlinear internal excitations on the load sharing behavior of a compound planetary gear set," Proceedings of the Institution of Mechanical Engineers, Part C: Journal of Mechanical Engineering Science, vol. 230, no. 7-8, pp. 1048-1068, 2015.

[15] X. Qiu, Q. Han, and F. Chu, "Load-sharing characteristics of planetary gear transmission in horizontal axis wind turbines," Mechanism and Machine Theory, vol. 92, pp. 391-406, 2015. 
[16] F. M. Ye, "Dynamic load sharing behaviors of planetary gear train system with unequal moduli and pressure angles," Journal of South China University of Technology, vol. 39, no. 1, pp. 117123, 2011 (Chinese).

[17] S. Y. Ye and S. J. Tsai, "Loaded tooth contact analysis of powersplit gear drives considering shaft deformation and assembly errors," in Proceedings of the ASME International Design Engineering Technical Conferences and Computers and Information in Engineering Conference, Boston, Mass, USA, 2015.

[18] J. Zhang, X. Tang, H. Yu, and L. Zou, "Multi-body dynamics and noise analysis for the torsional vibration of a power-split hybrid driveline," Proceedings of the Institution of Mechanical Engineers, Part K: Journal of Multi-body Dynamics, vol. 228, no. 4, pp. 366379, 2014.

[19] M. Delkhosh and M. S. Foumani, "Introduction and optimization of a power split continuously variable transmission including several fixed ratio mechanisms," Scientia Iranica, vol. 22, no. 1, pp. 226-234, 2015.

[20] C. Chen, "Power flow and efficiency analysis of epicyclic gear transmission with split power," Mechanism and Machine Theory, vol. 59, no. 4, pp. 96-106, 2013.

[21] T. J. Krenzer, "Tooth contact analysis of spiral bevel and hypoid gears under load," in Proceedings of the S.A.E. Earthmoving Industry Conference, Peoria, IL, USA, 1981.

[22] H. Dong, Y. Cao, and Z. Fang, "Dynamic vibration characteristic analysis for the power-split transmission system based on loaded tooth contact analysis," Shock and Vibration, vol. 2015, Article ID 871894, 15 pages, 2015.

[23] Y. Zhuo, X. Zhou, and C. Yang, "Dynamic analysis of doublerow self-aligning ball bearings due to applied loads, internal clearance, surface waviness and number of balls," Journal of Sound and Vibration, vol. 333, no. 23, pp. 6170-6189, 2014. 




Advances in

Operations Research

\section{-n-m}
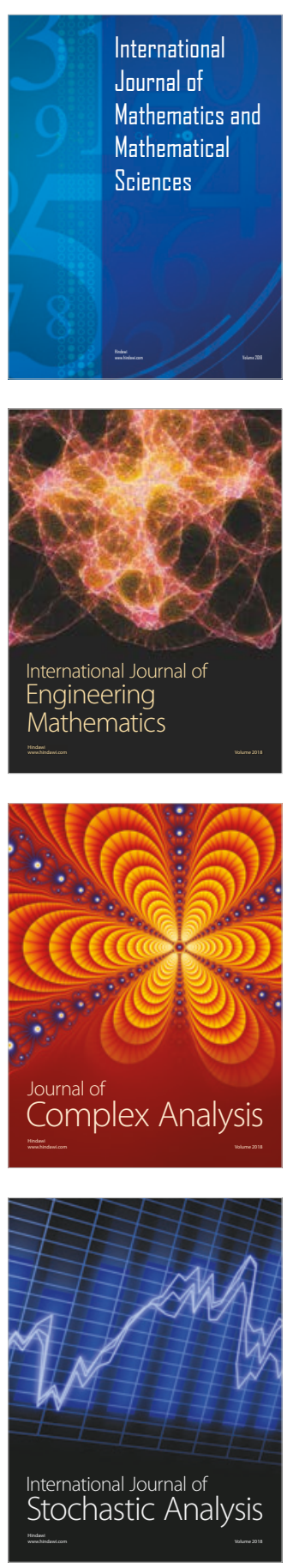
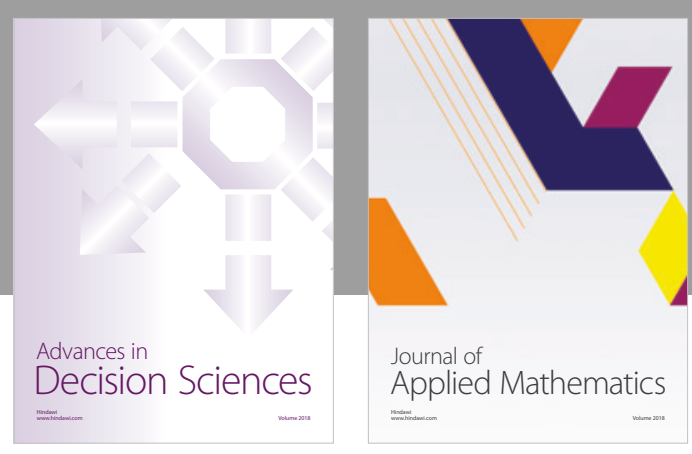

Journal of

Applied Mathematics
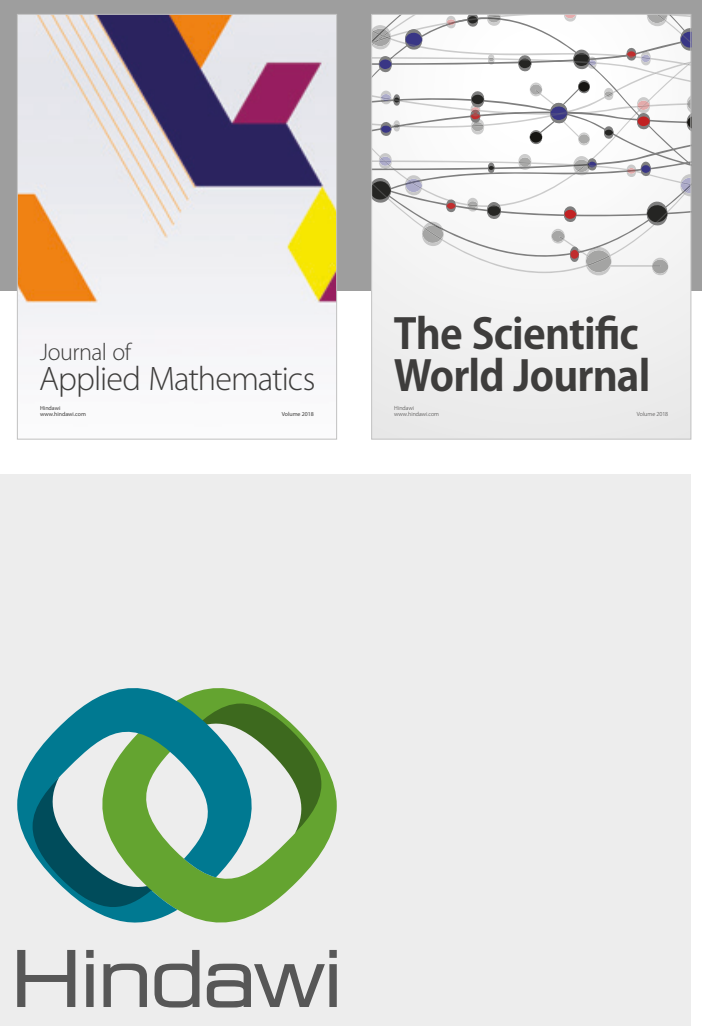

Submit your manuscripts at

www.hindawi.com

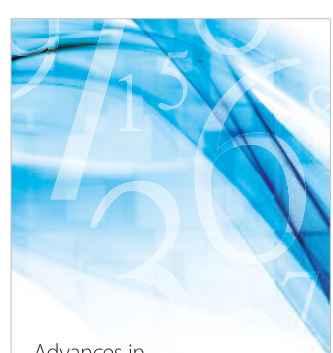

Advances in
Numerical Analysis


Mathematical Problems in Engineering

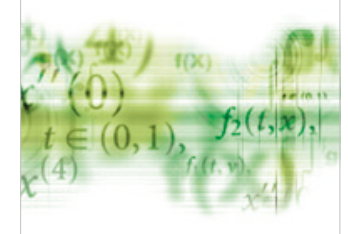

International Journal of

Differential Equations

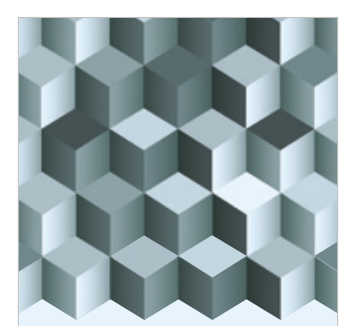

Journal of

Function Spaces

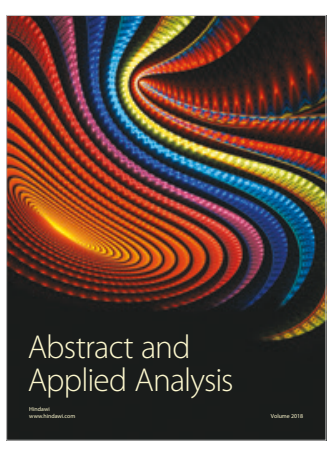

The Scientific

World Journal

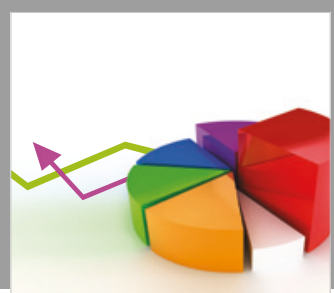

Journal of

Probability and Statistics
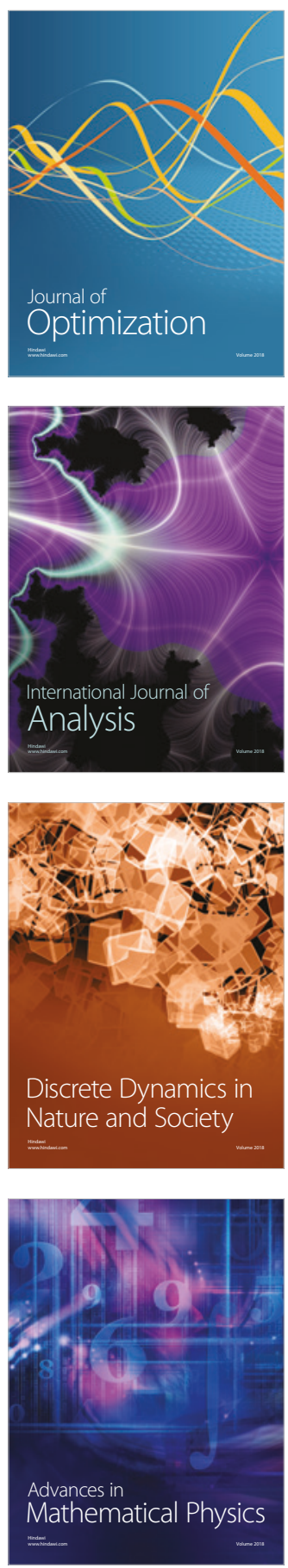